\title{
WILEY-VCH
}

DOI: 10.1002/ ((please add manuscript number))

Article type: Review

\section{Nanoarchitectured Array Electrodes for Rechargeable Lithium- and Sodium-ion Batteries}

Yang Xu, Min Zhou, and Yong Lei*

Dr. Y. Xu, Dr. M. Zhou, Prof. Y. Lei

Institute of Physics \& IMN MacroNano (ZIK), Ilmenau University of Technology, Prof. Schmidt-Str. 26, 98693, Germany

E-mail: yong.lei@tu-ilmenau.de

Keywords: nanoarchitectures, arrays, electrodes, lithium-ion batteries, sodium-ion batteries

\begin{abstract}
Rechargeable ion batteries have contributed immensely to shape the modern world and been seriously considered for the efficient storage and utilization of intermittent renewable energies. To fulfill their potential in future market, superior battery performance of high capacity, great rate capability, and long lifespan is undoubtedly required. In the past decade, along with discovering new electrode materials, the focus has been shifting more and more toward rational electrode designs because the performance is intimately connected to the electrode architectures, particularly their designs at the nanoscale that can alleviate the reliance on the materials' intrinsic nature. The utilization of nanoarchitectured arrays in the design of electrodes has been proven to significantly improve the battery performance. This review provides a comprehensive summarization of structural features and fabrications of the nanoarchitectured array electrodes, and highlights some of the latest achievements in the area of both lithium- and sodium-ion batteries. Finally, future challenges and opportunities that would allow further development of such advanced electrode configuration are discussed.
\end{abstract}




\section{WILEY-VCH}

\section{Contents}

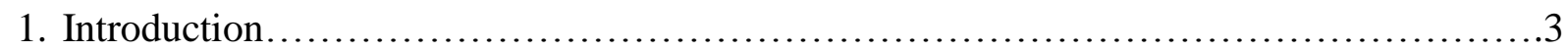

2. Basic aspects of the NAA electrodes for rechargeable ion batteries......................6

2.1. Electrochemistry of rechargeable ion batteries...................................

2.2. Structural features and superiorities of the NAA electrodes.............................

3. Fabrication of the NAA electrodes.......................................................

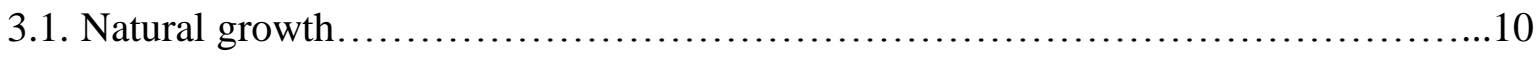

3.1.1. Vapor-phase growth........................................................

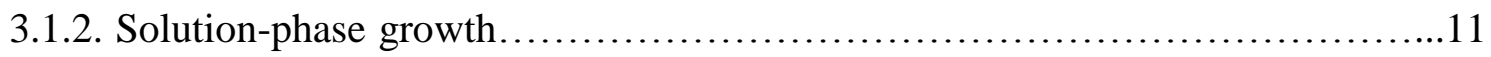

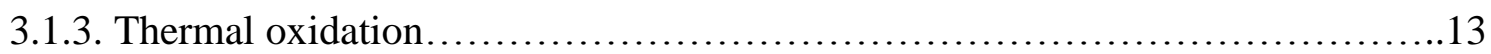

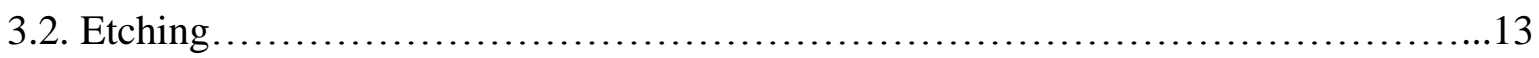

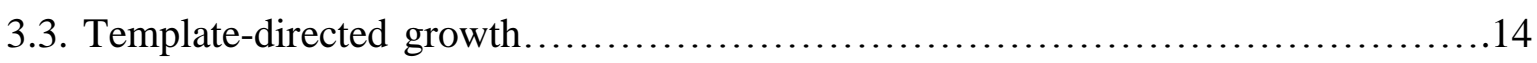

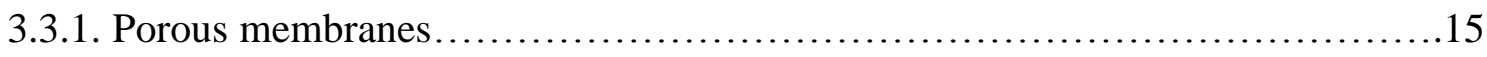

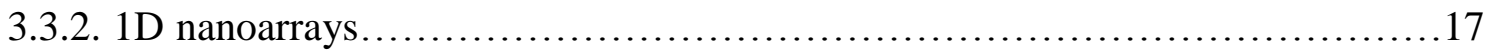

3.3.3. Colloidal crystal templates..................................................... 19

4. Electrochemical performances of the NAA electrodes................................20

4.1. Electrochemical performances of the NAA electrodes for LIBs.....................21

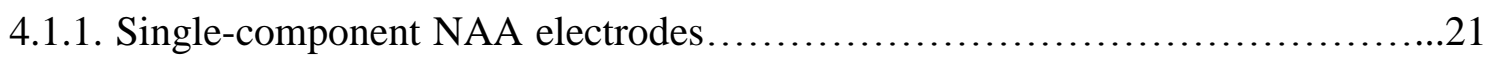

4.1.2. Binary-component NAA electrodes.......................................23

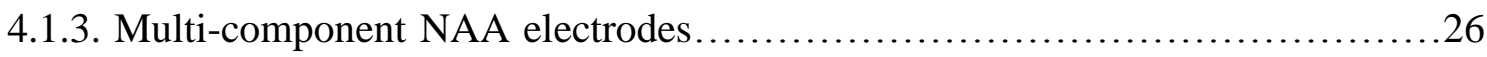

4.2. Electrochemical performances of the NAA electrodes for SIBs.....................27

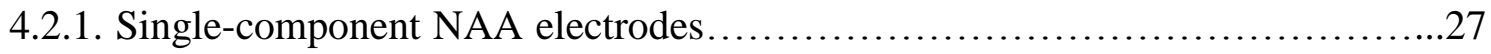

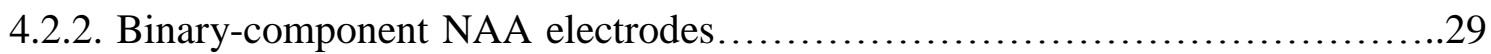

4.2.3. Multi-component NAA electrodes............................................ 30

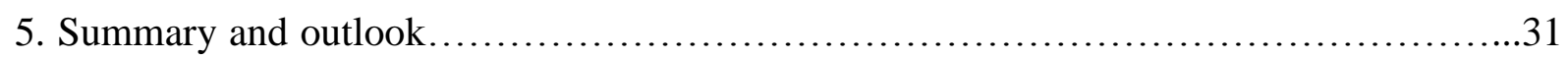

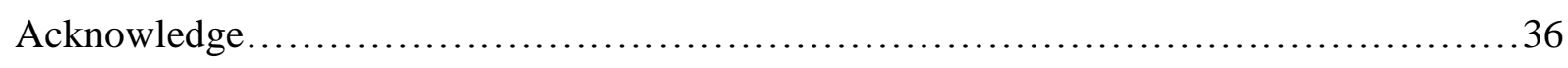

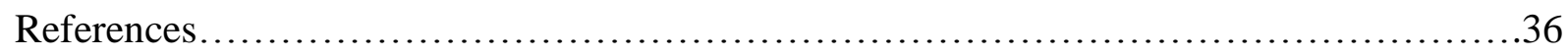

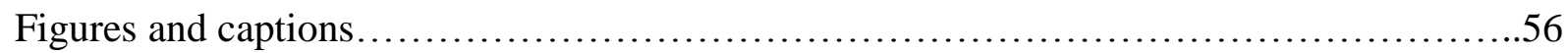

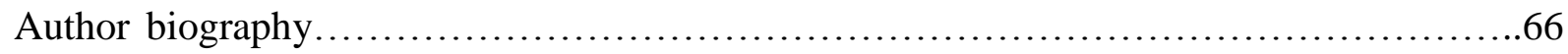




\section{WILEY-VCH}

\section{Introduction}

Energy issue has become a growing concern over the past decade as a result of largely increased energy demand, combined with the increase in the price of refined fossil fuels and their unsustainable nature as well as the need to control $\mathrm{CO}_{2}$ emission associated with global warming. This calls for alternative energy sources that are renewable and environmentally responsible for both energy generation and storage, such as solar radiation, waves, and wind. However, the uneven distribution and unpredictable nature have raised problems when using these renewable energy sources; that is to say, they will not have the anticipated impact unless we find an efficient way to store and use the electricity produced by them. Electrochemical energy storage (EES) technologies based on batteries have been showing considerable promise because of their appealing features including high round-trip efficiency, flexible power and energy characteristics to meet different grid functions, long cycle life, and low maintenance. ${ }^{[1]}$ Such features allow batteries to become a viable energy storage technology for the integration of renewable energy sources that provide intermittent energy into the grid.

Among the various available EES technologies, lithium-ion batteries (LIBs) are certainly a contender because of the much higher energy stored per unit weight or volume compared to other conventional batteries (lead-acid, nickel-hydride, redox-flow, and high-temperature batteries). The higher energy density comes from the higher cell voltage ( $3 \sim 5 \mathrm{~V}$, Figure 1) due to the use of non-aqueous electrolytes along with higher capacity values (up to $4000 \mathrm{mAh}$ $\left.\mathrm{g}^{-1}\right)$ compared to aqueous electrolyte-based battery systems $(<2 \mathrm{~V}) .{ }^{[2,3]}$ Since the first commercial launch by Sony, LIBs have conquered the market of portable electronics during the past two decades. They are now being intensively pursued for transportation applications, including hybrid electric vehicles (HEV), plug-in hybrid electric vehicles (PHEV), and electric vehicles (EV). The representative EV model is Model S (Tesla Motor) that employs LIBs to realize all-wheel drive with dual motors, reaching a maximum driving range of 270 miles and possessing an environment-friendly feature of zero emissions. LIBs are also being 


\section{WILEY-VCH}

seriously considered for the efficient storage and utilization of intermittent renewable energies due to the rising demands for power storage units that supplement irregular power generation and consumption patterns and also realize the future power network system, such as the Smart Grid. LIBs with good capabilities and rapid response property are appropriate for smoothing short time power variation through frequency regulation. ${ }^{[4]}$ The market is at its initial stage and worth approximately 2 billion dollars, but is expected to grow explosively up to 35 billion dollars by 2020 with an expansion of renewable energy supplies and the Smart Grid system. ${ }^{[5]}$

However, concerns over potentially rising costs and availability of global lithium resources have arisen because of the fact that most easily accessible lithium reserves are in remote or politically sensitive areas. ${ }^{[6-8]}$ The foreseeable price rising of lithium compounds will make EES technologies based on LIBs less affordable. Recently, rapidly growing attention has shifted to sodium-ion batteries (SIBs) due to the cost effectiveness and geographical distribution of sodium. Theoretically speaking, SIBs may not reach the energy density of that of LIBs because $\mathrm{Na}$ is three times heavier than Li. But given its suitable potential of $-2.71 \mathrm{~V}$ (vs. SHE) which is only $0.3 \mathrm{~V}$ more positive than that of Li, there is only a small energy penalty to pay, meaning that SIBs could find their more suitable application in the presence of a large grid support where the operation cost and longevity of the batteries are more important aspects of a whole system. ${ }^{[9]}$ In fact, the development of SIBs was parallel to that of LIBs through the 1980 's, ${ }^{[10-18]}$ but was completely shadowed by the accelerated process of LIBs that has dominated both research and commercial fields and led to the exponential growth in the portable electronics market in the 1990's. The first turning point of the research of SIBs appeared in 2000 when Stevens and Dahn reported that a high reversible capacity of $300 \mathrm{mAh}$ $\mathrm{g}^{-1}$, close to that of graphitic carbon for LIBs, has been demonstrated with hard carbon in a SIB, even though the cyclability wasn't sufficient for the practical battery application at that time. ${ }^{[19]}$ Afterwards, a series of important findings has intrigued the revisit of this topic during the 2000's. ${ }^{[20-23]}$ Research in SIBs has increased dramatically since 2010 (Figure 2), 


\section{WILEY-VCH}

especially in the last few years, ${ }^{[24-35]}$ and is now in full swing to discover new electrode materials, solve the existing barriers, and thereby enable the emerging EES technologies to become available for large-scale energy storage in the near future.

It is well known that important battery performance characteristics such as storage capacity and rate capability are mainly determined by the electrochemical properties of the electrode materials and the electrode architectures. Recent reviews from different research groups have systematically summarized the electrode materials of LIBs and SIBs, ${ }^{[1,36-44]}$ where the dependence of the performance on the materials has been exemplified in the evolution of both batteries, showing that the discovery of new compounds or new morphologies or both has been the key factor to empower the advance of this EES technology. Keeping in mind that finding a perfect electrode material is difficult by the complexity of requirements for the material's intrinsic properties, research interests have been building up on the rational designs of the electrode architectures because the performance is also intimately connected to the electrode architectures, particularly their designs at the nanoscale. ${ }^{[36,45-48]}$ With this content, several electrode architectures have been highlighted as their significant features can improve the LIB performance (nanocables, ${ }^{[49]}$ core-shell structure ${ }^{[50]}$ and hollow-porous structure ${ }^{[51]}$ ). Such architecture-induced advantages definitely can be applied to both LIB and SIB electrodes and a parallel study in this regard could allow us to gain more targeted understandings. Given the fact that the relatively larger size of Na-ion than that of Li-ion (1.02 $\AA$ vs. $0.76 \AA$ ) makes the requirements for the materials' intrinsic properties even more complex, rational designs of the electrode architectures are more urgently needed to achieve comprehensive improvement of SIB performance. ${ }^{[52]}$

In this review, we focus on one of the advanced design strategies-nanoarchitectured array (NAA)-toward high-performance electrodes with taking both LIBs and SIBs into considerations. First of all, basic electrochemistry fundamentals of rechargeable ion batteries and the structural features of the NAAs are provided. Secondly, we summarize the fabrication 


\section{WILEY-VCH}

of the NAA electrodes using template-free and template-assisted approaches. Thirdly, we review the recent progress of using the NAA electrodes for LIBs and SIBs, highlighting the improvements of the battery performance. Finally, based on the current development, the future challenges and opportunities in this direction are also discussed. We hope that this review can give us a better understanding of the uniqueness of the NAAs and shed light on their future applications on batteries and other possible energy storage and conversion technologies.

\section{Basic aspects of the NAA electrodes for rechargeable ion batteries}

\subsection{Electrochemistry of rechargeable ion batteries}

The principle of battery operation is same for LIBs and SIBs: the ions are shuttled between the cathode (positive) and anode (negative) electrode through a non-aqueous (or aqueous) electrolyte during the charge-discharge cycles, a process similar to a rocking chair, and the system is termed as "rocking-chair battery". The electrochemical potential values of cathode $\left(\mu_{\mathrm{C}}\right)$ and anode $\left(\mu_{\mathrm{A}}\right)$ must be higher than the HOMO and lower than the LUMO of the electrolyte, respectively, in order to obtain a stable battery cell (Figure 3a). ${ }^{[53,54]}$ A typical working process is illustrated in Figure 3b. During charge, ions are extracted from cathode (above $3.0 \mathrm{~V}$ vs. $\mathrm{Li}^{+} / \mathrm{Li}$ or $\mathrm{Na}^{+} / \mathrm{Na}$ ) and inserted into anode (below $1.0 \mathrm{~V}$ vs. $\mathrm{Li}^{+} / \mathrm{Li}$ or $\mathrm{Na}^{+} / \mathrm{Na}$ ). Meanwhile, electrons are thermodynamically pumped "uphill" from cathode to anode through the external circuit. On discharge, the reverse mechanism occurs, allowing the reaction to proceed "downhill” and thus converting chemical energy into electrical energy.

Thermodynamically, the energy storage or release in an electrochemical reaction is determined by the Gibbs free energy change $(\Delta G)$ :

$$
\Delta G=-n F V
$$

where $n$ is the number of electron transfer, $F$ is the Faraday constant, and $V$ is the cell voltage (electromotive force of the cell reaction). In a battery system, the energy density $(E)$ is subjected to the reversible capacity $(Q)$ of the materials and $V$, which is generally determined 


\section{WILEY-VCH}

by the ion accommodation ability of the active materials and electrochemical potential difference between the cathode and anode, respectively:

$$
E=Q V
$$

From a kinetic point of view, compared to the cell voltage $V$ derived from thermodynamic description, the voltage drops off ("electrode polarization") when current is drawn from the battery because of kinetic limitations of reactions and of other processes must occur to produce current flow during operation. ${ }^{[55]}$ Power density $(P)$ represents the rate of energy storage or release and is a kinetic characteristic to reflect the current rate capability of the battery. It can be expressed as:

$$
P=I V_{\text {out }}
$$

where $V_{\text {out }}$ is the output voltage with current $I$ flowing. The electrode polarization is due to three different kinetics effects: activation polarization, ohmic polarization, and concentration polarization. ${ }^{[55,56]}$ Lower polarization can lead to lower total voltage drop, which is favored for enhancing the output voltage. This can be realized by rationally designing the electrode architectures.

\subsection{Structural features and superiorities of the NAA electrodes}

To realize rechargeable ion batteries with both high energy and power density, it is important to understand the ion and electron transport pathways inside a battery system. Whether it is a charging or discharging process, the transport pathways of the charges generally include: (1) ions transport in the electrolyte to reach the electrode/electrolyte interface; (2) ions transport in the electrode; (3) ions and electrons associate in the electrode to perform the electrochemical reaction; (4) electrons transport in the electrode and current collector. Simultaneously reducing the resistances of the four transport pathways can essentially reduce the kinetics limitation, and it should be the guideline for rationally designing the electrode architectures. 


\section{WILEY-VCH}

Following the above guideline, it is worth emphasizing that certain drawbacks exist in the majority of the currently available commercial ion battery electrodes that consist of active material powders, polymer-based binders and conductive additives, forming as thin films on the order of hundreds of micrometers thick. First, the random stacking of the active material and conductive additive can increase ion transport resistance in the electrolyte to reach the bottom of the film. Second, the incomplete contact between ions and active material can lead to incomplete electrochemical reactions, causing the loss of storage capacity. Third, both large ion and electron transport resistance exist in the electrode because of the disordered nanocrystals network where the charges jump through inter-particle contacting area, which is fatal to achieve great rate capability. In addition, the extra weight of the additives can cause more loss of specific capacity and the post-treatment with a high pressure can lead to a dense or even damaged structure.

NAA represents a promising architecture for a wide spectrum of energy-related implementations because of its superior geometric characteristics. ${ }^{[57-60]}$ When it comes to the rechargeable ion battery application, the NAA electrodes consist of the oriented and architectured nanoarray directly growing on the conductive substrate that works as both current collector and structure support. The building unit of the array can be various, such as nanowires, nanorods, nanotubes, nanosheets, nanowalls, etc. The architecture of the array falls in a wide range depending on the type of the active materials and the way to integrate them. For instance, a core-shell or branched structure can be obtained with two materials, while a sandwich structure can be realized with three materials. Except for the general benefits deriving from the morphologic characteristics, the NAA electrodes possess prominent features that can improve the four transport pathways simultaneously as well as additional benefits. As shown in Figure 4 (using nanorod array as an example), the features and benefits include:

(1) An interconnected electrolyte-filled pore network that enables rapid ion transport in the electrolyte: the interval space formed between neighboring subunits provides a 


\section{WILEY-VCH}

directional ion diffusion pathway from electrolyte to reach the inner region of electrode, making it possible that individual nanoarchitecture participates in the electrochemical reaction.

(2) A short ion diffusion length that minimizes ion transport resistance in the electrode: the short length scale of the subunits directly growing on the current collector can decrease the ion transport resistance in the solid.

(3) A large surface area that maximizes electrochemical reactions in the electrode: the large surface area can lead to more electrode/electrolyte contact and active sites.

(4) A directional pathway that enables fast electron transport: the establishment of the integrated architecture with a robust adhesion to the substrate provides numerous fast electron-transport accesses to the current collector. Electrons can quickly move from the active redox sites and be collected at the substrate along the directional pathways.

(5) The arrayed architecture allows for the accommodation of the strain of ion insertion along a specific orientation. The interval space can act as a protective structural buffer zone to alleviate the damage caused by volume expansion-contraction and against agglomeration, pulverization, and exfoliation of active materials during repeating charge/discharge cycles. The rigid arrayed structure and robust connection between the substrate and the material can enhance the stability of the electrode.

(6) A hetero-component system can be obtained by constructing two and even more material component into specific architectures. Each component is tailored to fulfill specific function and different components are engineered in a way such that a synergetic effect can take place, generating additional benefits except for the above structural features.

As a result, the NAA electrodes can reach high energy density by enhancing storage capacity from feature (1) and (3), high power density by enhancing rate capability from feature (2) and (4), prolonged lifespan from feature (5), as well as additional benefits from feature (6). Moreover, such design also realizes an additive-free electrode and saves the 


\section{WILEY-VCH}

complex technological process of mixing multiple components and high-pressure posttreatment, potentially reducing the cost.

\section{Fabrication of the NAA electrodes}

As mentioned previously, the NAAs directly grow on the conductive substrate that acts as both current collector and structure support. Therefore, the principle of choosing fabrication strategies should be the ability of growing nanoarrays directly on various conductive substrates (e.g., Cu, Ti, Si, Ni, alloys, stainless steel (SS), carbon cloth, etc.) in order to realize binder- and additive-free battery electrodes. Many strategies have been developed and they can be classified into three categories as shown in Figure 5, namely, natural growth, etching, and template-directed growth.

\subsection{Natural growth}

Natural growth, just as the name implies, is to directly grow arrays on the substrates by using a variety of straightforward techniques without accessorial steps. Therefore, it is the most commonly used strategy to fabricate the NAAs among the three categories. Depending on the growth environment, this strategy can be categorized into three approaches: vaporphase growth, solution-phase growth, and thermal oxidation.

\subsubsection{Vapor-phase growth}

Vapor-phase growth mainly includes chemical vapor deposition (CVD) and physical vapor deposition (PVD). Both depositions are quite straightforward processes where the substrate is exposed to one or more precursors that react and/or deposit on the substrate surface to produce the NAAs. Typically, both deposition techniques require high temperature $\left(>500^{\circ} \mathrm{C}\right)$ and vacuum as well as a cooling water system to dissipate large heat loads. CVD involves the chemical reactions using the vapor with the elements of the target material and other indispensable gases in the reaction chamber. Frequently, volatile by-products are also produced, which are removed by gas flow through the reaction chamber. Generally, the growth mechanisms are vapor-liquid-solid (VLS), vapor-solid-solid (VSS), and vapor-solid 


\section{WILEY-VCH}

(VS). CVD is preferentially chosen to fabricate metal and alloy nanoarray anodes on various substrates, which includes $\mathrm{Si}$ nanowire arrays, ${ }^{[61-65]} \mathrm{Ge}$ nanowire arrays, ${ }^{[66]}$ and Si-Ge nanowire arrays. ${ }^{[67]}$ Carbonaceous anodes have also been produced using CVD, including single-walled ${ }^{[68-70]}$ and multi-walled carbon nanotube (SW- and MW-CNT) arrays, ${ }^{[71,72]}$ carbon nanofiber (CNF) and nanosheet (CNS) arrays, ${ }^{[73-75]}$ and graphene nanosheet arrays. ${ }^{[76,77]}$ In addition, CVD is also applicable to produce compound-based NAA electrodes for rechargeable ion batteries (e.g., $\mathrm{MoO}_{3-\mathrm{x}}{ }^{[78]} \mathrm{SnO}_{2},{ }^{[79]} \mathrm{SiO}_{2},{ }^{[80]} \mathrm{FeVO}_{4},{ }^{[81]} \mathrm{Ni}_{\mathrm{x}} \mathrm{Si}_{\mathrm{y}},{ }^{[82-85]}$ and $\left.\mathrm{C} / \mathrm{TiC}^{[86]}\right)$. PVD uses physical process, such as evaporation and sputtering, to generate a vapor of the target material, which is then directly deposited into arrays on the substrate. It is often chosen to synthesize the NAAs with special morphological features. Ge ${ }^{[87,88]}$ and carbon ${ }^{[89]}$ nanocolumn arrays were fabricated by glancing angle deposition (GLAD) and pulsed laser deposition (PLD), respectively. GLAD is also used to fabricate $\mathrm{Si}-\mathrm{Cu}$ helical array. ${ }^{[90]} \mathrm{A}$ unique dynamic shadowing growth (DSG)-based PVD method is employed to design and fabricate different amorphous $\mathrm{Si}$-based nanoarrays (multilayer $\mathrm{Cu} / \mathrm{Si}, \mathrm{Cu}$-side-coated $\mathrm{Si}$, uniform CuSi composite, and composition-graded CuSi composite). ${ }^{[1,92]}$

\subsubsection{Solution-phase growth}

Solution-phase growth to fabricate the NAAs is based on a liquid-solid growth mechanism and involves a process where a substrate is immersed in a reaction solution containing soluble salt(s) of the precursor(s) and the NAAs generate on the surface of the substrate after a treatment at certain temperature. Compared to vapor-phase growth, solution-phase growth usually proceeds at a temperature lower than $300^{\circ} \mathrm{C}$ and doesn't require high vacuum, thus considerably reducing the complexity and cost of the fabrication. Two facile approaches fall into this category: hydro-/solvothermal method and solution deposition. Hydro-/solvothermal method proceeds in a temperature range of $100 \sim 300^{\circ} \mathrm{C}$ and with a pressure higher than $1 \mathrm{~atm}$. There are two factors that contribute to the formation of the arrayed architectures. On one hand, the oriented growth can form the materials in an arrayed manner because the intrinsic 


\section{WILEY-VCH}

anisotropy of crystal structures controls the materials to grow preferentially along certain crystallographic direction(s). On the other hand, surfactants, usually with the amphiphilic nature, can control the growth rate of different crystallographic facets by absorbing on the facets so that anisotropic growth happens because of the resultant different surface tension between the liquid and solid. The most important feature of hydro-/solvothermal method is versatility and generality, as well as easy operation. The versatility is reflected by the diverse morphologies of the resultant arrays (e.g., nanowires, nanorods, nanotubes, nanosheets, nanowalls, branched structures, and their combinations). The generality gives the preparation a wide space of the types of materials. So far, hydro-/solvothermal method has been used to produce the NAA electrodes in a vast range of materials that covers oxides $\left(\mathrm{TiO}_{2},{ }^{[93-98]}\right.$ $\left.\mathrm{H}_{2} \mathrm{Ti}_{2} \mathrm{O}_{5} \cdot \mathrm{H}_{2} \mathrm{O},{ }^{[99]} \mathrm{Fe}_{2} \mathrm{O}_{3},{ }^{[100-102]} \mathrm{SnO}_{2},{ }^{[103-107]} \mathrm{WO}_{3},{ }^{[108]} \quad \mathrm{MnO}^{[109]} \quad \mathrm{VO}_{\mathrm{x}},{ }^{[110-113]}\right)$, metal vanadates, ${ }^{[114]}$ metal titanates, ${ }^{[115-117]}$ hydroxides, ${ }^{[118,119]}$ sulfides, ${ }^{[120,121]}$ phosphates, ${ }^{[122]}$ and fluorides. ${ }^{[123]}$ Solution deposition includes electro-deposition (ED) and chemical bath deposition (CBD, also known as electroless deposition ${ }^{[124]}$ ), both of which can be performed at a temperature lower than $100^{\circ} \mathrm{C}$ from water-based electrolytes in an ambient atmosphere. Solution deposition has two main attributes that make it well suited for fabricating the NAAs. First, it can be used to grow materials on the substrates with complex texture. Second, it can be scaled down to the deposition of a few atoms or up to large dimensions. ${ }^{[125]}$ Metal-based nanocone arrays (NCAs), including $\mathrm{Ni},{ }^{[126-129]} \mathrm{Co},{ }^{[130]}$ and $\mathrm{Cu}^{[131]} \mathrm{NCAs}$, have been mainly produced by directly electrochemical depositing from a $\mathrm{pH}$ buffer (typically $\mathrm{H}_{3} \mathrm{BO}_{3}$ )containing electrolyte on the surface of the corresponding metal substrate. These NCAs can work as the nanoarchitectured electron collector and transport medium as well as the structural support and inactive confining buffer, and integrate with active materials to form the NAA electrodes. In addition, by annealing the $\mathrm{Cu}(\mathrm{OH})_{2}$ nanoarrays fabricated by $\mathrm{ED}, \mathrm{Cu}-$ based oxide NAAs are obtained and used as either single-phased or composite electrodes. ${ }^{[132-}$ ${ }^{134]}$ In comparison, CBD is employed to mainly fabricate oxide- and sulfide-based NAAs 


\section{WILEY-VCH}

because the solution-phased growth of oxides and sulfides can be conducted under the ambient atmosphere at a relatively lower temperature. On the sulfide side, $\mathrm{Ni}_{3} \mathrm{~S}_{2}$ nanowire arrays, ${ }^{[135]} \mathrm{Cu}_{2} \mathrm{~S}$ nanowire arrays, ${ }^{[136]} \mathrm{SnS}_{2}$ nanowall arrays ${ }^{[137]}$ and $\mathrm{MoS}_{2}$ nanosheet arrays ${ }^{[138]}$ have been produced using $\mathrm{CBD}$ and used as the NAA electrodes. On the oxide side, $\mathrm{Co}_{3} \mathrm{O}_{4}$ nanowire arrays, ${ }^{[139]} \mathrm{FeO}_{\mathrm{x}}$ nanotube arrays, ${ }^{[140]} \mathrm{ZnCo}_{2} \mathrm{O}_{4}$ nanorod arrays, ${ }^{[141]} \mathrm{Co}$-doped $\mathrm{NiO}$ nanoflake arrays, ${ }^{[142]}$ and $\mathrm{CuO}-\mathrm{MnO}_{2}$ core-shell nanosheet arrays ${ }^{[143]}$ have been obtained.

\subsubsection{Thermal oxidation}

Thermal oxidation is also a vapor-phase technique that forces an oxidizing agent to diffuse into the substrate at high temperature $\left(>400^{\circ} \mathrm{C}\right)$ and react with it. As the name itself indicated, this method is often used to fabricate oxide NAAs by directly oxidizing metal substrates in an atmosphere. It may use either water vapor or molecular oxygen as the oxidant that is consequently called either wet or dry oxidation. Catalysts may be involved sometimes to guide the growth of the arrays. The most common case is to grow $\mathrm{CuO}$ nanoarrays directly from $\mathrm{Cu}$ foils in an oxygen atmosphere. ${ }^{[144]} \mathrm{NiO}$ nanowall arrays are also fabricated on $\mathrm{Ni}$ foils using a plasma-assist oxidation method where oxygen gas is leaked into a vacuum chamber as oxidizing agent. ${ }^{[145]}$

\subsection{Etching}

Etching involves corroding the surface of the conductive substrates and subsequently producing NAAs by the reactions between the substrate and etching materials through either chemical or electrochemical process. Depending on that the etching material is solution or gas, it can be consequently recognized as wet or dry etching.

Wet etching can be conducted either chemically or electrochemically. Chemically wet etching has been frequently employed to prepare $\mathrm{Si}$ and $\mathrm{CuO}$ NAAs. A metal-assisted chemical etching approach is usually used to fabricate Si nanowire arrays. ${ }^{[146-148]}$ This etching process consists of three steps: ${ }^{[149]}(1)$ the oxidant is preferentially reduced at the surface of the noble metal due to the catalytic activity of the noble metal on the reduction of the oxidant; 


\section{WILEY-VCH}

(2) the holes generated due to the reduction of the oxidant diffuse through the noble metal and are injected into the Si that is in contact with the noble metal; (3) the Si is oxidized by the injected holes and dissolved at the Si/metal interface by HF. Metal-assisted chemical etching has a few advantages over VLS mechanism-based CVD method when growing Si nanowires. ${ }^{[149]}$ The process to produce $\mathrm{CuO}$ NAAs using chemically wet etching is much simpler and essentially a solution-based corrosion where $\mathrm{Cu}$ foil is immersed in alkaline (typically $\mathrm{NaOH}$ ) solution. ${ }^{[150,151]}$ Additionally, anodization is an electrochemically wet etching method to grow oxide arrays as a result of oxidation of an anodically connected metal in an acidic electrolyte solution. The arrays are formed on the metal surface after chemical reaction between the metal atoms and an oxidizing agent in the electrolyte. Anodization is a popular method to prepare $\mathrm{TiO}_{2}$ nanotube arrays due to the relatively low environmental impact, low cost, and fast oxidation process. The as-prepared $\mathrm{TiO}_{2}$ nanotube arrays can be either directly used as NAA electrodes ${ }^{[152-158]}$ or as a scaffold to integrate with other active materials, forming the composite NAA electrodes. ${ }^{[159-164]}$ Besides, NiO nanorod arrays ${ }^{[165]}$ and $\mathrm{Cu}(\mathrm{OH})_{2}{ }^{[166]}$ nanoneedle arrays also have been prepared by anodization on $\mathrm{Ni}$ and $\mathrm{Cu}$ foil, respectively.

Compared to wet etching, dry etching is used mainly for preparing Si nanoarrays. Si nanohole arrays with a depth of around $2 \mu \mathrm{m}$ are produced by using reactive ion etching (RIE) on pre-patterned $\mathrm{Si}$ wafer with $\mathrm{SF}_{6}$ and Ar as etching gases. A subsequent wet etching further forms Si nanowire arrays. ${ }^{[167]}$ Inductive coupled plasma (ICP) is another dry etching method to prepare Si nanorod arrays, where polystyrene (PS) spheres are used to configure the periodic layout. ${ }^{[168]}$ In addition, plasma-enhanced CVD (PECVD) is employed to create nanoarrays on an organic material polyimide (PI) with $\mathrm{CF}_{4}$ etching. ${ }^{[169]}$

\subsection{Template-directed growth}

Template-directed synthesis is a versatile fabrication method used to produce nanomaterials with desirable structures. The versatility is attributed to two aspects. On one 


\section{WILEY-VCH}

hand, various materials with diverse structures, morphologies and compositions can be obtained through the template synthesis route. On the other hand, a variety of materials ranging from inorganic/organic compounds to polymers and even biological materials can be employed as templates without limitation to membranes. Considerable effort so far has been devoted to fabricating electrodes of rechargeable batteries using templates. According to the requirement that the NAAs should directly connect to conductive substrate so that the resultant electrodes don't contain any binder or additive, hard templates are dominantly employed in this regard. The so-called "hard templates" normally possess well-confined void in the form of channels, pores, or connected hollow space. The greatest advantage of template synthesis is the achievement of the NAAs in large scale with well-defined shape, precisely controlled size, and predefined spatial orientation/arrangement. The size and shape of the NAAs can be effectively adjusted by simply changing the geometric features of the templates, and the spatial orientation/arrangement can be predefined by the spatial structure of the templates, which can be maintained on a substrate even without the support of the templates. Generally, the synthesis process contains three steps: (1) precursors fill in templates through incorporation or impregnation; (2) products grow through reactions; (3) products are obtained by removing templates. Commonly used hard templates to prepare the NAA electrodes can be classified into three types: porous membranes, one-dimensional (1D) nanoarrays, and colloidal crystal templates. Depending on their own characteristics, various synthetic techniques can be integrated with these hard templates, such as hydro-/solvothermal, sol-gel process, ED, CVD, atomic layer deposition (ALD), thermal decomposition, and so on.

\subsubsection{Porous membranes}

The most commonly used porous membranes for templated synthesis of the NAA electrodes include anodic aluminum oxide (AAO) and "track-etched" polymeric membranes such as polycarbonate (PC). Both templates are commercially available. 


\section{WILEY-VCH}

AAO membrane is prepared electrochemically from $\mathrm{Al}$ foil and has a self-ordered, honeycomb-like and highly oriented pore array structure. The pore diameter, pore density, and pore length can be tuned by anodizing $\mathrm{Al}$ foil at different conditions (e.g., acid, potential, temperature, and time). ${ }^{[170-173]}$ By changing the acid and potential as well as wet-chemical pore-widening process, the pore diameter and density can be tuned in a wide range of 10 400 $\mathrm{nm}$ and $10^{9} \sim 10^{11}$ pore $\mathrm{cm}^{-2}$, respectively. By changing the anodization time, the pore length can be tuned from several tens of nanometers to several tens of micrometers. It should be emphasized that the high controllability on the geometric parameters of the AAO template results in the high controllability on those of the resulting arrays since the formed solid product inside the pores replicates the shape of the void space in the template. ${ }^{[174-178]}$ Harsh conditions such as acidic or alkaline etching are usually required to remove the AAO membrane.

The AAO template fabricated through self-organization process has a poly-domain structure, meaning the honeycomb-like pore arrangement is in short-range order but longrange disorder, which consequently leads to the same arrangement of the resulting nanoarrays. To obtain perfectly ordered nanoarrays, nano-imprinted AAO templates emerged by anodizing the surface pre-patterned $\mathrm{Al}$ foil ${ }^{[179]}$ and have been largely developed recently. ${ }^{[180-}$ ${ }^{184]}$ In contrast to the short-range ordered pore arrangement of the self-organized AAO, the pore arrangement and inter-pore distance of the nanoimprinted AAO depend only on the initial surface patterning that have different pore arrangement (triangular, rectangular and hexagonal) and long-ranged order. Therefore, such perfectly ordered arrangement can be inherited by the resulting nanoarrays.

PC membrane is made by a "track-etch" method that entails bombarding a nonporous sheet of the desired material with nuclear fission fragments, to create damage tracks in the material, and then chemically etching these tracks into pores. ${ }^{[185]}$ The pores are cylindrical with uniform diameter ranging from a few nanometers to micrometers. The size of the pores 


\section{WILEY-VCH}

depends on various factors, such as the nature and energy of incident particles, the target material, and etching condition (e.g., temperature, nature of etchant, pre-etch storage conditions, etc.). ${ }^{[186,187]}$ Compared to the AAO membrane, the pore density is relatively lower and the pores are randomly distributed across the membrane surface, and thus the periodic arrangement is missing. However, the PC membrane can be removed by mild chemical etching such as chloroform $\left(\mathrm{CH}_{2} \mathrm{Cl}_{2}\right)$.

By taking advantages of vertically aligned porous structures, arrayed electrodes in various forms can be fabricated using both templates combining with solution-phase or vapor-phase synthesis methods. Electrochemical deposition has been predominantly employed as a solution-phase synthesis method to deposit metal and metal oxide NAA electrodes. Using AAO membrane as template, $\mathrm{Cu}_{2} \mathrm{O}$ nanorod arrays, ${ }^{[188]} \mathrm{MnO}_{2}$ nanowire arrays, ${ }^{[189]} \mathrm{NiSn}$ nanowire and nanotube arrays ${ }^{[190]}$ have been prepared directly on the conductive substrate. Using the same way with PC membrane as the template, Ge nanotube arrays ${ }^{[191]}$ and $\mathrm{SnCo}$ nanowire arrays ${ }^{[192]}$ are fabricated. It is a popular idea to electrochemically deposit metal inside the porous membranes so that the obtained nanoarrays can work as current collector, such as $\mathrm{Cu},{ }^{[193-198]} \mathrm{Al}^{[199,200]}$ and $\mathrm{Ni}^{[201,202]}$ Such metal-based arrayed current collectors have been integrated with active materials in a wide range to form core-shell NAA electrodes. Typical vapor-phase synthesis methods include CVD, ALD and thermal evaporation. Using AAO membrane as template, CNT array electrode is obtained by a one-step CVD process ${ }^{[203]}$ and coaxial C-Si-C nanotube array electrode is realized by a three-step CVD process. ${ }^{[204]}$ ALD is also a versatile method to deposit nanoarrays with homogeneous or heterogeneous structures, such as $\mathrm{SnO}_{2}, \mathrm{TiO}_{2}$ and $\mathrm{SnO}_{2}-\mathrm{TiO}_{2}$ nanotube array electrode. ${ }^{[205]}$

\subsubsection{D nanoarrays}

1D nanoarrays such as nanowire, nanorod, and nanotube arrays possess the geometric characteristics that suit with the features of the NAAs, thus can be used as templates to prepare the NAA electrodes with the target materials. The general process consists of three 


\section{WILEY-VCH}

steps: (1) synthesis of the 1D nanoarrays; (2) integration with or transformation into the target materials; (3) removal of the 1D nanoarrays. The geometric features of the $1 \mathrm{D}$ nanoarrays can be tuned by the synthesis parameters; therefore, those of the resulting NAAs can be tuned consequently. The most commonly used 1D nanoarray templates for electrode fabrication are $\mathrm{ZnO}$ and metal hydroxycarbonates. Depending on the way they participate with the synthesis, two processes can take place, namely physical integration and chemical transformation.

In a physical integration process, the template works only as morphology modifier and structure support, and the active material is physically coated on the surface of the template by various methods where no chemical reactions take place between the material and template. $\mathrm{ZnO}$ nanorod arrays are preferentially employed to prepare nanotube arrays because of the rigid structure. Many nanotube array electrodes have been reported using $\mathrm{ZnO}$ nanorod arrays as template, including Si-based (e.g., Si nanotubes, ${ }^{[206,207]} \mathrm{Si}-\mathrm{Ge}$ double layered nanotubes, ${ }^{[208]}$ and coaxial C-Si-C nanotubes ${ }^{[209]}$ ) and oxide-based (e.g., $\mathrm{TiO}_{2}$ nanotubes, ${ }^{[210]} \mathrm{SnO}_{2}$ nanotubes, ${ }^{[211]}$ and $\mathrm{SnO}_{2}-\mathrm{Fe}_{2} \mathrm{O}_{3}$ composite nanotubes ${ }^{[212]}$ ) active materials. The $\mathrm{ZnO}$ template can be removed by either solution etching or high-temperature vapor reduction. Normally, the widely used $\mathrm{ZnO}$ nanoarrays are randomly oriented because of the natural growth of seed layer in precursor solution. However, by combing colloidal crystal templating and polymer etching techniques, surface of the seed layer can be patterned, and thus $\mathrm{ZnO}$ growth occurs selectively on the exposed $\mathrm{ZnO}$ seed layer to create well ordered $\mathrm{ZnO}$ nanoarrays, which results in well-ordered active material nanoarrays after removing $\mathrm{ZnO}$ template. ${ }^{[213]}$

In a chemical transformation process, not only do the templates work as morphology modifier and structure support, but also they participate in the chemical reactions to produce the active material. Therefore, the template can be removed in-situ, which is beneficial for maintaining the overall structure of the product. Metal hydroxycarbonate $\mathrm{M}\left(\mathrm{CO}_{3}\right)_{\mathrm{x}}(\mathrm{OH})_{\mathrm{y}}\left(\mathrm{H}_{2} \mathrm{O}\right)_{\mathrm{z}}(\mathrm{M}=\mathrm{Co}, \mathrm{Ni}, \mathrm{Fe}, \mathrm{Mn}, \mathrm{Zn}, \mathrm{Ge}$, and their combinations $)$ are prominently used because their crystal structures are highly compatible with multiple metal cations. The 


\section{WILEY-VCH}

metal hydroxycarbonate nanoarrays can be synthesized by a simple hydro/solvothermal method on different substrates and chemically transfer to the corresponding oxide nanoarrays by a post-annealing treatment. So far, a large amount of works has reported single or hybrid oxide NAA electrodes based on this chemical transformation process, which includes Co, ${ }^{[214-}$ ${ }^{221]} \mathrm{Ni},{ }^{[222-224]} \mathrm{Ni}-\mathrm{Co},{ }^{[225-227]} \mathrm{Zn}-\mathrm{Co},{ }^{[228,229]}$ and Zn-Ge oxides. ${ }^{[230]}$ In addition, depending on the concentration of Co precursor, $\mathrm{ZnO}$ nanorod arrays have been used to fabricate both $\mathrm{CoO}$ $\mathrm{ZnO}$ nanoarrays by physical integration and $\mathrm{ZnCo}_{2} \mathrm{O}_{4}$ nanoarrays by chemical transformation. $^{[231]}$

\subsubsection{Colloidal crystal templates}

The typical colloidal crystal templates to fabricate the NAA electrodes are PS and poly(methyl methacrylate) (PMMA) as well as poly(phenylene oxide) (PPO) spheres. They can self-assemble into two-dimensional (2D) and three-dimensional (3D) ordered arrays under appropriate conditions that can further work as templates. The diameter of the colloidal spheres is uniform with a range from several tens of nanometers to several micrometers. The shape and size of the array templates as well as synthesis methods mainly determine those of the resulting NAAs. Through a pretreatment of thermal annealing or plasma etching, ${ }^{[232-236]}$ the diameter and interspace of the spheres can be finely tuned, resulting in the array templates with a widely tunable size and shape. Usually, either chemically dissolving in organic solvents or annealing in oxygen-containing atmosphere can remove the templates. It is worth pointing out that, due to the requirement of binder- and additive-free, only the colloidal templates prepared on conductive substrates and the resulting NAAs directly used as electrodes will be discussed here despite of the fact that a large amount of the porous arrays have been fabricated in this way but used as powder materials for battery electrodes.

2D ordered arrays are a monolayer of monodispersed colloidal spheres arranged in a hexagonal close-packed pattern on substrate. They are usually used as surface nanopatterning template to fabricate highly ordered and oriented 1D nanoarrays. As we discussed, 2D ordered 


\section{WILEY-VCH}

PS template can combine with dry etching process in order to prepare highly ordered and highly oriented Si nanorod arrays, where the template is used as surface mask to configure the periodic layout on the surface of Si wafer.

3D ordered arrays are multilayered colloidal spheres predominantly packed in face centered cubic $(f c c)$ assembles on substrate. The general process using the 3D ordered arrays as template involves three steps: (1) synthesis of the 3D ordered arrays; (2) filtration with precursor solution under proper conditions (multiple times if necessary); (3) post-treatment to obtain product and remove the template. Depending on the amount of the filtrated precursor solution, the 3D ordered arrays can be used as either volume template or surface template. Ordered macroporous $\mathrm{SnO}_{2}$ film has been fabricated on Pt-coated glass using 3D PMMA template. ${ }^{[237]}$ Similar structures of $\mathrm{V}_{2} \mathrm{O}_{5}$ are prepared using 3D PPO and PS template on $\mathrm{Al}$ foil and indium tin oxide (ITO)-coated glass. ${ }^{[238,239]}$ Except for active materials, ordered macroporous current collector can also be fabricated. Ni macroporous arrays are obtained through a combination of 3D PS templated electrodeposition and the subsequent electropolishing process, and used as the arrayed current collector to integrate with $\mathrm{MnO}_{2}$ to construct a NAA electrode. ${ }^{[240]}$

\section{Electrochemical performances of the NAA electrodes}

As we highlighted in the previous section, the NAAs as electrodes can provide multiple advantages: rapid ion transport in electrolyte, short ion diffusion in electrode, large surface area, directional electron transport pathway, and high electrode stability. Designing and optimizing suitable NAA electrodes to make full use of the above advantages are of particular significance to improve the electrochemical performance of the batteries. So far tremendous effort has been made in this regard. We will review here some important and recent progress in the fields of both LIBs and SIBs. We want to categorize the NAA electrodes into three categories, namely single-, binary-, and multi-component electrodes, in order to highlight the detailed structural merits of the NAAs. 


\section{WILEY-VCH}

\subsection{Electrochemical performances of the NAA electrodes for LIBs}

\subsubsection{Single-component NAA electrodes}

Single-component NAAs refer to the nanoarrays that are single-phased and directly connect to substrate. The nanoarrays are the electroactive material and the substrate works as the current collector. Single-component NAA electrodes consist of 1D (nanowire, ${ }^{[61,66,78,139,241-245]}$ nanorod, ${ }^{[100,103,151,225,246-248]}$ and nanotube ${ }^{[120,191,206,211,249,250]}$ ), 2D (nanosheet, ${ }^{[77,138,219,251-256]}$ nanoflake, ${ }^{[109,142,257]}$ and nanowall ${ }^{[101,145,258-260]}$ ) or 3D (branched structure $^{[77,261-265]}$ ) nanostructures. Rogers and Paik, et al. demonstrated that, despite tremendous stresses and volume changes involved in charge-discharge cycles, robust performance in $\mathrm{Si}$ based LIBs is possible by structuring $\mathrm{Si}$ into nanotube arrays (Figure 6a). ${ }^{[266]}$ Such anode exhibits high initial Columbic Efficiency $(\mathrm{CE},>85 \%)$ and stable capacity retention (> $80 \%$ after 50 cycles) due to mechanics that are dominated by free surfaces (Figure 6b). Theoretical analysis suggests that the additional free surfaces provided by the empty interior spaces of the tubes improve the ability of these structures to accommodate volume expansion such that a strongly anisotropic expansion in which $400 \%$ volumetric increases are accomplished with only relatively small $(<35 \%)$ changes in the axial dimension (Figure 6c). A systematic study of the contact resistance effect on the rate capability of $\mathrm{TiO}_{2-}$ based electrodes is conducted where three types of electrodes were compared: conventional, randomly oriented nanotubes, vertically aligned nanotube arrays with sealed and unsealed caps. ${ }^{[267]}$ Both the experimental results and theoretical analysis proves that the directly grown arrays on a current collector show superior rate capability than conventional electrodes, suggesting the improved kinetics and electronic conductivity of the nanoarray electrode. Except for the general structural advantages, 2D nanoarrays possess large exposed crystallographic facets whose high single-crystallinity can facilitate charge diffusion by reducing grain boundaries and provide more $\mathrm{Li}$ insertion channels. Well-aligned $\mathrm{Li}_{4} \mathrm{Ti}_{5} \mathrm{O}_{12}$ (LTO) nanosheet arrays grown directly on Ti foil exhibit an excellent rate capability with a 


\section{WILEY-VCH}

reversible capacity of 163 and $78 \mathrm{mAh} \mathrm{g}^{-1}$ at 20 and $200 \mathrm{C}$, respectively (Figure 6d and e), and an outstanding cycling performance with $\pm 7.5 \%$ capacity loss after 3000 cycles at $50 \mathrm{C}$ with the capacity retention of $124 \mathrm{mAh} \mathrm{g}^{-1}$ (Figure 6f). ${ }^{[116]}$ Beneficial from the bendable Ti substrate, a flexible battery coupled with the commercial $\mathrm{LiCoO}_{2}$ as cathode was assembled, and it can be fully charged to $3 \mathrm{~V}$ within $30 \mathrm{~s}$ and able to light a red LED at the bended state. In this work, the long and short side of the nanosheets are roughly along the [011] and [100] direction, respectively, giving rise to the exposed (01-1) facet. Such $\{111\}$ facets of spinel LTO might exhibit higher ion intercalation electrochemistry and presumably contribute to faster interfacial ion transfer and facile charge transport, for which it is better to have suitable simulations to provide deeper insights for similar works. 3D nanoarrays involve the secondary building blocks to form a hierarchical structure that can simultaneously provide high surface area and an intricate transportation network as well as new physicochemical properties arising from the secondary architecture. 3D hierarchical porous $\mathrm{NiCo}_{2} \mathrm{O}_{4}$ nanocluster arrays on nickel foam were fabricated in a fashion that $\mathrm{NiCo}_{2} \mathrm{O}_{4}$ nanowires are rooted in each of the $\mathrm{NiCo}_{2} \mathrm{O}_{4}$ nanosheets. ${ }^{[268]}$ This unique structure presents a high reversible capacity of $976 \mathrm{mAh} \mathrm{g}^{-1}$ at $200 \mathrm{~mA} \mathrm{~g}^{-1}$ with good cycling stability and rate capability.

It is worth emphasizing that charge transport has been considered as a key factor that is bound to influence any nanostructure-based energy storage approach. With the superior electrochemical performance being demonstrated by using nanoarrays as single electrode of LIBs, one can imagine that, taking one step further, if a battery consists of both nanoarray cathode and anode, their structural advantages can be taken to the maximum in a way that the pathways and resistances of charge transport can be significantly reduced and thus power and energy density can be considerably improved. Very recently, Lee and Rubloff, et al. reported an all-in-one nanopore battery array by dedicatedly utilizing the vertical nanopores of AAO template. ${ }^{[269]}$ In this all-in-one battery, an array of nanotubular electrode and a liquid electrolyte are confined inside of the nanopores. Integrated current collector ( $\mathrm{Ru}$ ) and 


\section{WILEY-VCH}

electroactive material $\left(\mathrm{V}_{2} \mathrm{O}_{5}\right)$ are conformably fabricated at two ends of the nanopores by controlled-conformability ALD to limit the deposition depth of both materials, where the ALD process allows the anode-cathode electrical isolation with precisely controlled distance by taking advantage of the length of the nanopores (Figure 7a and $\mathbf{b}$ ). With pristine $\mathrm{V}_{2} \mathrm{O}_{5}$ at one end as cathode and prelithiated $\mathrm{V}_{2} \mathrm{O}_{5}$ at the other end as anode, the parallel asymmetric nanoarrays achieve an areal density of $2 \times 10^{9} \mathrm{~cm}^{-2}$. Because of the highly-oriented and integrated nanotubular electrode design that facilitates fast ion and electron transport, the nanobattery delivers a capacity of 178 and $82 \mathrm{mAh} \mathrm{g}^{-1}$ at 1 and $150 \mathrm{C}$, respectively, and retains more than $80 \%$ of initial capacity after 1000 cycles (Figure $7 \mathbf{c}$ and $\mathbf{d}$ ).

\subsubsection{Binary-component NAA electrodes}

Binary-component NAA electrodes are hybrid nanoarrays with one component as main electroactive material and the other as functional component. The functional component is integrated primarily to either improve charge transport or structural stability. We want to point out that there is sometimes overlap between the two functions; for instance, a conductive scaffold can facilitate electron transport and support electrode structure at the same time. In this section, we will focus on the primary function of the second component.

Two approaches have been developed to improve charge transport by introducing the second component: inner conductive scaffold and outer conductive coating. The inner conductive scaffold acts as current collector and allows the direct growth of the active material on it. Such binary structure possesses direct electron transport and shorter $\mathrm{Li}^{+}$ diffusion pathways as well as high contact surface area between the material and electrolyte. Simon's group gave a prototype study of $\mathrm{Cu}-\mathrm{Fe}_{3} \mathrm{O}_{4}$ core-shell nanoarrays as cathode fabricated via AAO templating method (Figure 8a). ${ }^{[270]}$ They demonstrated that the power density is improved by a factor of 6 when the electrode featuring composite nanoarrays is employed to replace the planar electrodes. The capacity at the $8 \mathrm{C}$ rate is $80 \%$ of the total capacity and is sustained over 100 cycles (Figure 8c). They found that the cells retain full 


\section{WILEY-VCH}

capacity for numerous cycles when cycling at high rates (Figure 8b), evidencing the merits of $\mathrm{Cu}$ nanoarray current collector. It is known that mechanical breakdowns of 1D nanoarrays happen during battery operation, especially for conversion/alloy mechanism-based materials due to the reconstruction of crystal structures and/or huge volume change, which can cause the nanostructures to lose electrical contact with substrate. A 2D conducting network based on conductive $\mathrm{TiSi}_{2}$ nanonets was proposed to greatly reduce this problem. ${ }^{[271]} \mathrm{A}$ systematic study was carried out to compare the performance of $\mathrm{TiSi}_{2}-\mathrm{Si}$ composite based on 2D nanonets and 1D nanowires anode (Figure 8d). Great structural stability of the nanonetsbased composite electrode is observed where it exhibits higher capacity and higher retention at different operation conditions as well as better rate capability (Figure 8e), highlighting that the $2 \mathrm{D}$ nanonets used as current collector provide multiple charge transport pathways from any part of the nanonets. Importantly, the 3D bicontinuous feature can simultaneously guarantee the high electrical conductivity and fast electrolyte-ion transport within the whole scaffold. 3D Ni scaffolded $\mathrm{MnO}_{2}$ was constructed by Braun et al. (Figure 8f and g) and delivered very large battery charge and discharge rate with minimal capacity loss. ${ }^{[240]}$ The composite cathode retains $76 \%$ of its capacity when discharged at $185 \mathrm{C}$ and $38 \%$ when discharged at $1114 \mathrm{C}$ (Figure 8h). A full cell coupled with graphite anode can be 90\% charged in 2 minutes. Such bicontinuous conductive scaffold enables optimization to match the characteristic kinetics of a given battery chemistry. Except for using metal NAAs as current collector $\left(\mathrm{Ti}^{[272,273]} \mathrm{Cu},{ }^{[195,198,274-279]} \mathrm{Ni},{ }^{[202,280-284]} \mathrm{Fe},{ }^{[285]} \mathrm{Co},{ }^{[217]}\right.$ and $\left.\mathrm{Al}^{[200]}\right)$, the conductive scaffold concept has been applied to many materials by using CNTs as current collector. ${ }^{[68,70,75,286-293]}$ In both cases, the weight ratio between the current collector and active material needs to be carefully balanced because the energy density of the cell could be largely influenced if the current collector either is electrochemically inactive (e.g. metal or alloy) or has considerably lower ion storage capacity comparing to the active material. The outer conductive coating generally uses carbonaceous materials, ${ }^{[147,294]}$ conducting polymers, ${ }^{[107,295]}$ 


\section{WILEY-VCH}

and compounds ${ }^{[108,161,296]}$ to increase the electrical conductivity. A mesoporous thin layer of the conducting polymer poly(3,4-ethylenedioxythiophene) (PEDOT) has been coated on the $\mathrm{V}_{2} \mathrm{O}_{5}$ nanobelt arrays directly grown on the 3D ultrathin graphite foam (UGF) (Figure 8i and j). ${ }^{[295]}$ This thin homogeneous layer not only facilitates the electron transfer around the $\mathrm{V}_{2} \mathrm{O}_{5}$, but also decreases the polarization and improves the reaction kinetics, and thus the cathode exhibits ultrafast and stable Li storage performance (Figure 8k). High specific capacities of $265 \mathrm{mAh} \mathrm{g}^{-1}$ at $5 \mathrm{C}$ and $168 \mathrm{mAh} \mathrm{g}^{-1}$ at $60 \mathrm{C}$ are achieved, which can maintain $98 \%$ of their values up to 1000 cycles. A high energy density of $\sim 240 \mathrm{~W} \mathrm{~h} \mathrm{~kg}^{-1}$ at a power rate of $23 \mathrm{~kW}$ $\mathrm{kg}^{-1}$ is also achieved because of the prolonged discharge plateau above $3.0 \mathrm{~V}$ deriving from the reduced polarization.

Long-term structural stability is extremely crucial for battery performance. Among different Li storage mechanisms, alloy and conversion mechanism involve reconstruction of crystal structure and thus large volume change, which can lead to exfoliation, pulverization, or agglomeration during repeating charge-discharge process, eventually causing active material to lose electric connection with current collector. It has been proven effective that using a second component to release the structure strains and/or confine the volume change can stabilize the electrode integrity and prolong the lifespan. ${ }^{[62,63,102,228,297-299]}$ As an example, vertically aligned Si-Ge double-layered nanotube (Si/Ge DLNT) arrays were proposed (Figure 9a) to minimize both the mechanical stress applied to the inner Si layer during lithiation and the electrochemical resistance, and utilize the merits of outer Ge layer with higher electrical conductivity, higher lithium ion diffusivity and smaller volume change comparing to $\mathrm{Si}^{\left[{ }^{[208]}\right.}$ The $\mathrm{Si} / \mathrm{Ge}$ DLNT electrode has a 2-fold higher areal capacity $(1.2 \mathrm{mAh}$ $\mathrm{cm}^{-2}$ ) compared to that of the Si nanotube (SiNT) electrode and better rate capacity retention at higher rates $(60 \%$ vs. $30 \%$ at the $3 \mathrm{C}$ rate) (Figure 9c). Calculations show that the maximum hoop strain in Si/Ge DLNT can be reduced compared to that in homogeneous SiNT, which is experimentally proven by the post-cycling measurement revealing that the $\mathrm{Si} / \mathrm{Ge}$ 


\section{WILEY-VCH}

DLNT retains it original shape without mechanical degradation (Figure 9b). The electrode integrity also can be maintained by the robust structural and electrical stability of the second component. ${ }^{[93,140,141,162,166]}$ For instance, branched $\mathrm{Co}_{3} \mathrm{O}_{4} / \mathrm{CuO}$ nanowire heterostructure arrays have been prepared such that the rigid $\mathrm{CuO}$ nanowire arrays provide persistent support during the conversion-based lithiation of $\mathrm{Co}_{3} \mathrm{O}_{4}$ (Figure 9d and e). ${ }^{[220]}$ When the arrays are used as anode at the rate of $200 \mathrm{~mA} \mathrm{~g}^{-1}$, no obvious capacity fading is observed in the first 140 cycles and a retention of $90.9 \%$ is achieved after 200 cycles (Figure 9f). A reversible capacity of $810 \mathrm{mAh} \mathrm{g}^{-1}$ can be maintained after 500 cycles with almost $100 \%$ retention at the rate of $1 \mathrm{~A}$ $\mathrm{g}^{-1}$, further demonstrating the long-term structural stability of the NAA electrode.

\subsubsection{Multi-component NAA electrodes}

Multi-component NAA electrodes consist of more than two components and each of them is tailored to satisfy different demands such as high energy density, high conductivity, and excellent mechanical stability. Coaxial sandwich structure and encapsulation have been proposed to organize the components. ${ }^{[70,98,163,194,204,209]}$ Manthiram et al. reported mesoporous $\mathrm{TiO}_{2}-\mathrm{Sn} / \mathrm{C}$ core/shell nanowire arrays on $\mathrm{Ti}$ foil where $\mathrm{Sn}$ formed by a reduction of $\mathrm{SnO}_{2}$ is encapsulated into $\mathrm{TiO}_{2}$ nanowires and the carbon layer is coated onto it (Figure 10a and b).${ }^{[99]}$ The structure design principle is to utilize the stable structure of the $\mathrm{TiO}_{2}$ nanowire core, high theoretical capacity of metallic Sn, and high conductivity of the carbon shell to effectively buffer the volume change, suppress cracking, and improve the conductivity. In return, the array anode exhibits enhanced electrochemical cycling and rate capability compared to the pure $\mathrm{TiO}_{2}$ and $\mathrm{TiO}_{2}-\mathrm{SnO}_{2}$ composite nanowires. At a low rate of $1 \mathrm{C}$, a capacity of $459 \mathrm{mAh} \mathrm{g}^{-1}$ with a high $\mathrm{CE}$ of around $99.9 \%$ is achieved (Figure 10c). While at a high rate of $10 \mathrm{C}$, the anode delivers a discharge capacity greater than $160 \mathrm{mAh} \mathrm{g}^{-1}$ and the retention of $84.8 \%$ after 100 cycles (Figure 10d). A capacity of $90 \mathrm{mAh} \mathrm{g}^{-1}$ can still be retained at $30 \mathrm{C}$. Nanoporous $\mathrm{Fe}_{2} \mathrm{O}_{3} / \mathrm{Fe}_{3} \mathrm{C}$-graphene heterogeneous arrays were reported to be fabricated by integrating few-layer graphene into an anodically self-organized $\mathrm{Fe}_{2} \mathrm{O}_{3}$ 


\section{WILEY-VCH}

nanoporous arrays through a CVD process, followed by a post-annealing treatment to partially convert electrochemically inactive $\mathrm{Fe}_{3} \mathrm{C}$ formed during CVD to active $\mathrm{Fe}_{2} \mathrm{O}_{3}$ (Figure 10f). ${ }^{[300]}$ In such structure, $\mathrm{Fe}_{2} \mathrm{O}_{3}$ with high theoretical capacity works as active material, inactive $\mathrm{Fe}_{3} \mathrm{C}$ improves the capacity retention owing to its high hardness, and graphene layers enhances the electrical conductivity of the electrode. Furthermore, a possible lithium storage effect at $\mathrm{Fe}_{2} \mathrm{O}_{3}-\mathrm{Fe}_{3} \mathrm{C}$ phase-interface provides the ability to store additional charge (Figure 10e). The anode delivers a capacity of $\sim 1120 \mathrm{mAh} \mathrm{g}^{-1}$ at a rate of $\sim 0.17 \mathrm{C}$ with $88 \%$ retention after 100 cycles and $\sim 520 \mathrm{mAh} \mathrm{g}^{-1}$ at a rate of $6.6 \mathrm{C}$ after 1000 cycles (Figure $\mathbf{1 0 g}$ and $\mathbf{h}$ ), giving the energy density of $\sim 920 \mathrm{Wh} \mathrm{kg}^{-1}$ and power density of $\sim 1830 \mathrm{~W} \mathrm{~kg}^{-1}$.

\subsection{Electrochemical performances of the NAA electrodes for SIBs}

SIBs have attracted rapidly growing attention due to the low cost of $\mathrm{Na}$ associated with its natural abundance in both and earth and decent energy density bestowed by its similar chemical nature to lithium. Many electrode materials of LIBs have been investigated as dropin replacement for SIBs because of the chemical similarity, but their deficient intrinsic properties often lead to unsatisfactory battery performances or even complete electrochemical inactivity, for which the larger size of Na-ion relative to Li-ion is generally believed to be responsible. ${ }^{[40-42]}$ This in turn motivates us to explore advanced electrode designs. Given the fact that research on electrode designs of SIBs is still in its infant stage compared to material searching, NAAs have been received a large amount of considerations as an advanced electrode design. Thus, it is of great importance to review the recent progress on this topic.

\subsubsection{Single-component NAA electrodes}

Since lower cycling stability and poorer rate performance are two distinctive drawbacks of most electrode materials of SIBs compared to those of LIBs due to the larger size of Na-ion, the advantages of NAAs, including robust electric connection, vertical alignment and sufficient interval space, are more crucial to achieve desirable battery performance. Nanoarrays in various morphologies have been prepared and directly employed as SIB 


\section{WILEY-VCH}

electrodes for different Na-storage mechanisms (i.e., alloy, ${ }^{[87,301-304]}$ conversion $^{[150,305,306]}$ and intercalation $\left.^{[110,152,153,307-309]}\right)$. Zhang et al. presented a scalable fabrication of flexible and porous $\mathrm{CuO}$ nanorod arrays (CNAs) by simply engraving commercial copper foils and a subsequent annealing treatment (Figure 11a). ${ }^{[305]}$ The CNAs anode delivers a high capacity of $640 \mathrm{mAh} \mathrm{g}^{-1}$ at a rate of $50 \mathrm{~mA} \mathrm{~g}^{-1}$, high rate capability of $200 \mathrm{mAh} \mathrm{g}^{-1}$ at a rate of $1 \mathrm{~A} \mathrm{~g}^{-1}$ (ca. $8 \mathrm{C}$ ), and good cycle stability of retaining a capacity of $290.6 \mathrm{mAh} \mathrm{g}^{-1}$ after 150 cycles at a rate of $200 \mathrm{~mA} \mathrm{~g}^{-1}$ (Figure $\mathbf{1 1 b}$ and c). The achieved electrochemical performance is attributed to easy diffusion of electrolyte into the inner area of the electrode by the porous structure and ample open space between nanorods, good electronic contact between nanorods and current collector that allows electrons flow from the bottom of the array, and electron transporting pathways enabled by the in-situ formed interconnected metallic $\mathrm{Cu}$ particles. In a similar spirit, sodium titanate (NTO) nanotube arrays were prepared by chemically engraving Ti foil (Figure 11d). ${ }^{[307]}$ The structure of NTO combines the advantages of layered $\mathrm{Na}_{2} \mathrm{Ti}_{3} \mathrm{O}_{7}$ and tunnel-type $\mathrm{Na}_{2} \mathrm{Ti}_{6} \mathrm{O}_{13}$. The openness of the crystal structure and the configuration of the NAAs provide more channels and shorter paths for easy Na-ion diffusion, ensuring great rate performance of $42 \mathrm{mAh} \mathrm{g}^{-1}$ at a rate of $3.2 \mathrm{~A} \mathrm{~g}^{-1}$ (Figure 11e). Meanwhile, the structural stability of NTO arrays and good electric contact between the array and Ti foil allows high capacity retention of $55 \mathrm{mAh} \mathrm{g}^{-1}$ after 5000 cycles at a rate of $400 \mathrm{mAh} \mathrm{g}^{-1}$ (Figure 11f). Very recently, nanoarrays with high regularity and strictly vertical alignment have been proposed as an effective electrode configuration for SIBs. Lei et al. reported the large-scale highly ordered Sb nanorod arrays prepared by nanoimprinted AAO template-assist method (Figure 11g). ${ }^{[301]}$ The arrays anode shows a high capacity of $620 \mathrm{mAh} \mathrm{g}^{-1}$ at the 100th cycle with a retention of $84 \%$ up to 250 cycles at a rate of $0.2 \mathrm{~A} \mathrm{~g} \mathrm{~g}^{-1}$ and superior rate capability of delivering the capacities of 579.7 and $557.7 \mathrm{mAh} \mathrm{g}^{-1}$ at 10 and $20 \mathrm{~A} \mathrm{~g}^{-1}$, respectively (Figure $\mathbf{1 1 h}$ and $\mathbf{i}$ ). Unlike the conventional nanoarrays, such highly ordered nanoarrays realize a perfect vertical alignment and concomitant large interval spacing in the true sense such that they offer direct 


\section{WILEY-VCH}

channels for Na-ions to fully contact with $\mathrm{Sb}$ nanorods without dead angles and sufficient volume buffer zone to release strains and prevent pulverization. A full cell coupling with the $\mathrm{P} 2-\mathrm{Na}_{2 / 3} \mathrm{Ni}_{1 / 3} \mathrm{Mn}_{2 / 3} \mathrm{O}_{2}$ cathode was constructed and shows good cycling life up to 250 cycles, high rate capability up to $20 \mathrm{~A} \mathrm{~g}^{-1}$, and large energy density up to $130 \mathrm{Wh} \mathrm{kg}^{-1}$.

\subsubsection{Binary-component NAA electrodes}

As we discussed in 4.1.2, the primary function of the second component is to enhance charge transport or/and structural stability. Similar approaches of outer conductive coating and inner conductive scaffold have been employed to improve SIB performance. Core-sheath structured Sn@carbon nanotube nanopillar arrays grown vertically on carbon paper (Sn@CNT-CP) use the CNT sheathing to not only enhance the electrical conductivity of the electrode but also provide buffering capability for the formation of $\mathrm{Na}_{\mathrm{x}} \mathrm{Sn}$ alloy, thus effectively sustaining the integrity of the electrode (Figure 12a and b). ${ }^{[302]}$ The anode maintains the capacities of 550, 445, and $377 \mu \mathrm{Ah} \mathrm{cm}^{-1}$ after 100 cycles at the rates of 50, 250, and $500 \mu \mathrm{A} \mathrm{cm} \mathrm{cm}^{-1}$, respectively. At high rates of 750 and $1000 \mu \mathrm{A} \mathrm{cm} \mathrm{cm}^{-2}$, the anode still achieves the capacities of 341 and $299 \mu \mathrm{Ah} \mathrm{cm}^{-2}$, respectively (Figure 12c). The potential practical application of the Sn@CNT-CP arrays was demonstrated by assembling a full cell using $\mathrm{Na}_{0.8} \mathrm{Li}_{0.12} \mathrm{Ni}_{0.22} \mathrm{Mn}_{0.66} \mathrm{O}_{2}$ cathode. It delivers a capacity of around $160 \mu \mathrm{Ah}$ after 40 cycles with a CE of $95.5 \%$. Shen and Fan, et al. demonstrated high capacity, high-rate, and durable Na-ion storage performance using single-crystalline long-range-ordered bilayered $\mathrm{VO}_{2}$ nanoarray electrodes (Figure 12d). ${ }^{[308]}$ The nanoarrays grew on double-face graphene foam and were coated with a thin $(\sim 2 \mathrm{~nm})$ additional graphene quantum dots (GQDs) layer (Figure 12e). During sodiation, the cathode exhibits a capacity of $306 \mathrm{mAh} \mathrm{g}^{-1}$ at a rate of $100 \mathrm{~mA} \mathrm{~g}^{-1}(1 / 3 \mathrm{C})$ and superior rate tolerance of being able to charge and discharge in a range of $1 / 3$ to $120 \mathrm{C}$, maintaining a capacity of $93 \mathrm{mAh} \mathrm{g}^{-1}$ at $120 \mathrm{C}$ (Figure 12f). It also shows good capacity retention of retaining $91 \%$ of the initial capacity after 500 cycles at a rate of $5 \mathrm{C}$ and $88 \%$ after 1500 cycles at $60 \mathrm{C}$ with a power density of $42 \mathrm{~kW} \mathrm{~kg}^{-1}$ at an 


\section{WILEY-VCH}

energy density more than $100 \mathrm{Wh} \mathrm{kg}^{-1}$. The homogeneous GQDs covering can effectively separate the $\mathrm{VO}_{2}$ nanobelts from each other and thus avoid agglomeration as well as minimize the dissolution of active materials. Moreover, its "stacking" feature can provide extra Na-ion storage venues between the graphene flakes. Introducing highly ordered conductive scaffold as current collector presents a promising way to exploit the benefits of high regularity and strictly vertical alignment. Highly ordered $\mathrm{Ni}-\mathrm{TiO}_{2}$ core-shell nanoarrays consisting of highly ordered $\mathrm{Ni}$ nanopillar arrays as current collector and thin layer of anatase $\mathrm{TiO}_{2}$ as active material were prepared by nanoimprinted AAO templating technique and ALD deposition (Figure 12h). ${ }^{[309]}$ Such architecture simultaneously offers fast electron transport, high ion accessibility, and excellent electrode integrity that are enabled by the high regularity and vertical alignment of the nanopillars (Figure 12g). Used as anode, the nanoarrays deliver a capacity of $\sim 200 \mathrm{mAh} \mathrm{g}^{-1}$ after 100 cycles at a rate of $50 \mathrm{~mA} \mathrm{~g}^{-1}$, and were able to retain a capacity of $\sim 95 \mathrm{mAh} \mathrm{g}^{-1}$ at a rate of $5 \mathrm{~A} \mathrm{~g}^{-1}$ and fully recover low rate capacity (Figure 12i). The results demonstrate the possibility of highly ordered heterostructured nanoarrays for $\mathrm{Na}$ energy storage to alleviate the reliance on the materials' intrinsic nature.

\subsubsection{Multi-component NAA electrodes}

The design principle of multi-component NAA electrodes for SIBs has the same essence as that for LIBs. In such system, each component is engineered to fulfill specific function, e.g., providing structure support, enhancing ion diffusion, and increasing electrical conductivity, and works together in an integrated manner. Despite the similarities between the $\mathrm{Li}$ and $\mathrm{Na}$ electrochemistry, it is reasonable to expect that certain functions used to work in LIBs may not work well or even inactive in SIBs because of the different kinetic limitations between the two systems, thus it calls for more dedicated considerations on the function of each component. So far only by a few examples have demonstrated the benefits deriving from multi-component NAAs for SIBs, more effort is needed on this topic in the future. For instance, a forest of Sn nanorods with a unique core-shell structure has been constructed on 


\section{WILEY-VCH}

viral scaffold that is genetically engineered to ensure a nearly vertical alignment upon selfassembly onto a metal substrate (Figure 13a and b). ${ }^{[304]}$ First, Ni-coated tobacco mosaic virus (TMV) is used as the structural scaffold to introduce nanohierarchy into Sn electrode so that the buffering spaces between each individual nanorod can accommodate the volume expansion of Sn while still maintaining high capacity loading per footprint. Second, Ni sublayer between the $\mathrm{Sn}$ and current collector establishes a highly conductive pathway for electrons. Third, a thin layer of carbon is coated over the active Sn sublayer to suppress possible aggregation and pulverization during the electrochemical reactions by diminishing the diffusion of Sn. Additionally, alloying between Ni and Sn can potentially enhance the robustness of $\mathrm{Sn}$ particles through intermetallic bonding. The resulting $\mathrm{C} / \mathrm{Sn} / \mathrm{Ni} / \mathrm{TMV} 1$ cys nanorod array anode provides a capacity of $722 \mathrm{mAh} \mathrm{g}^{-1}$ in the initial cycles and retain 405 $\mathrm{mAh} \mathrm{g}^{-1}$ after 150 cycles (Figure 13c), demonstrating great cycling life of nano-Sn SIB anode. Wafer-scale 3D hexagonal match-like Si/TiN/Ti/Ge nanorod arrays on Si substrate were fabricated by the consecutive nanosphere lithography, inductive couple plasma dry etching, and sputtering processes (Figure 13d). ${ }^{[303]}$ The Si hexagonal nanorod arrays provide an ordered and firmly structural support, and the amorphous Ge sheath layer is active material to store $\mathrm{Na}$, while TiN/Ti layer between $\mathrm{Si}$ and $\mathrm{Ge}$ acts as a current collector layer to improve the electrical conductivity and reduce the inner resistance of the whole electrode. The anode maintains an areal capacity of about $20 \mu \mathrm{Ah} \mathrm{cm}^{-2}$ after 200 cycles at a rate of $10 \mu \mathrm{A} \mathrm{cm} \mathrm{cm}^{-2}$ and the retention remains at about $90 \%, 80 \%, 70 \%, 60 \%$ and $50 \%$ at the rates of $20,50,100,150$ and $200 \mu \mathrm{A} \mathrm{cm}^{-2}$ (corresponding to 390, 350, 310, 270 and $230 \mathrm{mAh} \mathrm{g}^{-1}$ at the rates of $0.4,1$, 2, 3 and $4 \mathrm{~A} \mathrm{~g}^{-1}$ ) (Figure 13e and $\mathbf{f}$ ). The wafer-scale Si-based electrode portends a promising future for lab-on-chip micro/nano SIBs with practical applications in integrated circuit system.

\section{Summary and outlook}

LIBs have contributed immensely to shape the modern world by being the indispensable power source for portable devices. SIBs have begun to show prospective potential as an 


\section{WILEY-VCH}

alternative for LIBs owing to the comparable properties and abundant $\mathrm{Na}$ resources. The present study has reviewed the synthesis of the NAAs and recent progress of using NAA electrodes for LIBs and SIBs. It is highlighted that the NAAs are able to significantly enhance the electrochemical performance of LIB and SIB electrodes, bringing out higher capacity, better rate capability, longer cycling life, and many other favorable properties. Such improvements mainly originate from the unique architecture that provides both structural and composite advantages: oriented and facile diffusion pathways for both electron and ion transport, void spaces for restraining structural deviation of single unit, strong attachment to the electrode for avoiding mechanical and electrical separation, and synergetic effect of hetero-component system. Although great achievement and remarkable progress have been made in advancing NAA electrodes for LIBs and SIBs, there is still a long way to overcome the subsistent obstructions considering the practical realization, especially on the overall fullcell scope.

(1) Current electrode demonstrations mainly focus on half-cell system. It is important to note that the advancement in the NAA anode hasn't been followed to the same extent by the improvements in the NAA cathode, presumably owing to the fact that various ion-storage mechanisms can be found in anode, whereas it is limited to intercalation in cathode. Although the fundamental advancements of NAA anode is motivating, a full cell system needs to be thoroughly investigated using pair-matched anode and cathode and classified for its optimum performance dictated by the end application. The concept of NAAs can definitely be applied to cathode materials, ${ }^{[72,123,199,271,295]}$ which is even more urgent for SIBs given the fact that rapid progress of SIBs has just been made in recent years, leaving wide space for deep exploration. Nevertheless, it should be possible to expect parallel investigations with comparable attention on both NAA cathode and anode along the already developed avenues to achieve the break-through improvement of full cell performance. 


\section{WILEY-VCH}

(2) The process of battery miniaturization nowadays has been rapidly proceeding to keep pace with the size scaling-down of electronic technologies. To improve the areal capacity and maximize the energy density, an electrode needs to be evaluated under relatively higher mass loading in the configuration of full cell. Some current synthetic methods of the NAAs grow restricted amount of active materials, so good electrochemical performance can be achieved at such thin layers but yet may not be achieved at thicker layers due to various influences, such as charge diffusion and electrolyte penetration. Several approaches to increase mass loading rely on creating high porosity, which sacrifices the volumetric capacity of the electrodes. To be of practical use in micro-devices, comparable volumetric densities between the electrodes should be pursued. Additionally, mass matching between cathode and anode has direct effect on the full cell performance. For the future synthesis design aiming higher mass loading, it is necessary to increase the mass loading of the NAA anode (cathode) to match with that of cathode (anode). Therefore, balance between high mass loading and high energy/volumetric density should be more carefully handled.

(3) The development of personalization and diversification of portable and even wearable electronics have intrigued the new demand for arbitrary shaped devices and thus are requiring flexible or bendable batteries that can be used in flexional energy storage ${ }^{[310]}$ Research on this topic needs to focus equally on electrode design, flexible current collector, and shapeconformable solid electrolyte. Apparently, metal-based current collector dominantly used in conventional batteries is no longer fulfilling the requirement as stains generated from continuous folding action would crack the electrode and impair the electrochemical performance. A few types of flexible NAA electrodes based on the flexible current collectors have shown attractive prospect in constructing flexible batteries owing to the robust and

interlinked matrix of the current collectors. ${ }^{[125,229,287,293]}$ However, many are based on carbonaceous materials with low spatial density. To achieve flexible batteries, the current 


\section{WILEY-VCH}

collector should be carefully chosen or designed towards less void space and higher volumetric energy density as well as feasible integration with suitable solid electrolyte.

(4) Organic compounds enable flexible designs and structures compared to inorganic compounds, which potentially provides good mobility of alkali ions as electrode materials for rechargeable batteries. Other features such as lightweight, vast resources, solution processability and sustainability can provide more benefits. In addition, electrode performance is potentially manipulated by the molecular design with different functional groups in the structures. ${ }^{[30,311-313]}$ Substantial progress has been made during the past few years with all-organic rechargeable ion batteries being realized. ${ }^{[314,315]}$ However, only a few works are based on nanostructured materials $\left(\mathrm{LIBs}^{[316]}\right.$ and $\mathrm{SIBs}^{[317,318]}$ ), and no organic-materialbased NAA has been reported so far, presumably due to the lack of control on the growth of organic materials and suitable synthesis methods. The distinguish features of the organic electrode materials, i.e. lightweight and flexible structures, perfectly fit the requirement of the flexible or bendable batteries that are discussed in the last issue, thus it is materially important and technically desirable to utilize organic-material-based NAA electrodes and future work may focus on developing effective fabrication approaches to obtain such electrodes.

(5) Batteries are complex systems where a variety of chemical and physical processes take place, such as phase transitions, volume changes, side reactions, etc. within the nanoarchitectured configurations. In situ measurements allow direct monitoring and observing these processes and thus offer the ability to straightforwardly link these processes to the electrochemical response of the battery. Investigations of batteries using in situ measurements have proven extremely insightful. ${ }^{[319-322]}$ In particular, more complicated chemical and physical processes are expected in the 3D nanoarchitectured arrays due to the morphological complex, thus in situ techniques that are capable of providing dynamic information of the 3D geometry of the nanoarray electrodes are highly needed and the development of these techniques is expected to achieve a high data collection rate. 


\section{WILEY-VCH}

(6) Relevant to the above issue, it is also important to use computational techniques to gain fundamental understanding, diagnostics and designs of new electrochemical materials and their structures to optimize overall battery performance. A recent comprehensive review has summarized the power of computational approaches in gaining a fundamental understanding of the atomic-scale properties of cathode materials for LIBs and SIBs. ${ }^{[323]}$ The difference between Li- and Na-ion in a variety of compounds is also highlighted with respect to voltage, phase stability, and activation energy for ion mobility. ${ }^{[324]}$ With the increased interests in modeling surface structures and hetero-interfaces (either solid-liquid or solid-solid) of the NAAs and the more kinetics limitations in SIBs, advanced computational modeling and simulation for SIBs are desirable to unfold new chemical and physical process occurring in corporation with the advanced in situ measurements.

(7) Emergence of other rechargeable ion batteries such as $\mathrm{Mg}$ - and Al-ion batteries might challenge the supremacy of the monovalent ion system in the future. ${ }^{[325]}$ Investigations consider multivalent cations offering more than one electron per redox event, thereby offering higher energy density potentially at reduced cost. ${ }^{[326-329]}$ Although the non-aqueous and solid state chemistry and electrochemistry of multivalent metals is substantially more complicated than that of the monovalent alkali metals, it is reasonable to expect that rational electrode design such as the NAAs might present a great opportunity to assist the material research for these newly emergent battery systems.

Based on the fundamental understanding of the working principle of rechargeable ion batteries and gained experiences of rational electrode design, continuing efforts and new concepts are urgently required to overcome the existing challenges and push forward the comprehensive improvement of the electrochemical performance on the full-cell scope so that the commercialization of SIBs can be realized and development of electrical vehicles can be accelerated in the near future. 


\section{WILEY-VCH}

\section{Acknowledgements}

Financial supports from the European Research Council (ThreeDsurface: 240144), BMBF (ZIK-3DNanoDevice: 03Z1MN11) and German Research Foundation (DFG: LE 2249_4-1) are gratefully acknowledged.

Received: ((will be filled in by the editorial staff))

Revised: ((will be filled in by the editorial staff)) Published online: ((will be filled in by the editorial staff))

[1] D. Kundu, E. Talaie, V. Duffort, L. F. Nazar, Angew. Chem. Int. Ed. 2015, 54, 3431.

[2] M. V. Reddy, G. V. Subba Rao, B. V. R. Chowdari, Chem. Rev. 2013, 113, 5364.

[3] H. Shimotake, E. Voss, Progress in batteries and solar cells, JEC Press, 1987.

[4] G. Jeong, Y.-U. Kim, H. Kim, Y.-J. Kim, H.-J. Sohn, Energy Environ. Sci. 2011, 4, 1986.

[5] Energy Storage on the Grid-Long Duration Storage Systems, Pike Research Report, 2010.

[6] S. Fletcher, Bottled Lightning: Superbatteries, electric cars, and the new lithium economy, Macmillan, 2011.

[7] F. Risacher, B. Fritz, Aquat. Geochem. 2009, 15, 123.

[8] A. Yaksic, J. E. Tilton, Resour. Policy 2009, 34, 185.

[9] M. Hana, E. Gonzalo, G. Singh, T. Rojo, Energy Environ. Sci. 2015, 8, 81.

[10] A. van Zyl, Solid State Ionics 1996, 86, 883.

[11] M. S. Whittingham, Prog. Solid State Chem. 1978, 12, 41.

[12] A. S. Nagelberg, W. L. Worrell, J. Solid State Chem. 1979, 29, 345.

[13] C. Delmas, J.-J. Braconnier, C. Fouassier, P. Hagenmuller, Solid State Ionics 1981, 3, 165.

[14] K. Abraham, Solid State Ionics 1982, 7, 199.

[15] M. M. Doeff, Y. Ma, S. J. Visco, L. C. De Jonghe, J. Electrochem. Soc. 1993, 140, L169. 


\section{WILEY-VCH}

[16] T. Jow, L. Shacklette, M. Maxfield, D. Vernick, J. Electrochem. Soc. 1987, 134, 1730.

[17] Y. Ma, M. M. Doeff, S. J. Visco, L. C. De Jonghe, J. Electrochem. Soc. 1993, 140, 2726.

[18] R. C. Galloway, S. Haslam, J. Power Sources 1999, 80, 164.

[19] D. Stevens, J. Dahn, J. Electrochem. Soc. 2000, 147, 1271.

[20] R. Alcántara, M. Jaraba, P. Lavela, J. Tirado, Chem. Mater. 2002, 14, 2847.

[21] R. Alcántara, P. Lavela, G. F. Ortiz, J. L. Tirado, Electrochem. Solid-State Lett. 2005, 8, A222.

[22] H. Zhuo, X. Wang, A. Tang, Z. Liu, S. Gamboa, P. Sebastian, J. Power Sources 2006, $160,698$.

[23] S. Okada, Y. Takahashi, T. Kiyabu, T. Doi, J. Yamaki, T. Nishida, 210th ECS Meeting Abstracts 2006, MA2006-02, 201.

[24] Y. Wen, K. He, Y. Zhu, F. Han, Y. Xu, I. Mastsuda, Y. Ishii, J. Cumings, C. Wang, Nature Commun. 2014, 5, 4033.

[25] J. Sun, H. Lee, M. Pasta, H. Yuan, G. Zheng, Y. Sun, Y. Li, Y. Cui, Nature Nanotechnol. 2015, 10, 980.

[26] E. Lotfabad, J. Ding, K. Cui, A. Kohandehghan, W. Kalisvaart, M. Hazelton, D. Mitlin, ACS Nano 2014, 8, 7115 .

[27] Y. Xu, M. Zhou, X. Wang, C. Wang, L. Liang, F. Grote, M. Wu, Y. Mi, Y. Lei, Angew. Chem. Int. Ed. 2015, 54, 8768.

[28] L. Liang, Y. Xu, X. Wang, C. Wang, M. Zhou, Q. Fu, M. Wu, Y. Lei, J. Power Sources 2015, 294, 193.

[29] Y. Xu, E. Lotfabad, H. Wang, B. Farbod, Z. Xu, A. Kohandehghan, D. Mitlin, Chem. Commun. 2013, 49, 8973.

[30] C. Wang, Y. Xu, Y. Fang, M. Zhou, L. Liang, S. Singh, H. Zhao, A. Schober, Y. Lei, J. Am. Chem. Soc. 2015, 137, 3124. 


\section{WILEY-VCH}

[31] P. Barpanda, G. Oyama, S. Nishimura, S. C. Chung, A. Yamada, Nature Commun. 2014, 5, 4358 .

[32] N. Yabuuchi, M. Kajiyama, J. Iwatate, H. Nishikawa, S. Hitomi, R. Okuyama, R. Usui, Y. Yamada, S. Komaba, Nature Mater. 2012, 11, 512.

[33] K. Saravanan, C. Mason, A. Rudola, K. Wong, P. Balaya, Adv. Energy Mater. 2013, 3, 444.

[34] V. Raju, J. Rains, C. Gates, W. Luo, X. Wang, W. F. Stickle, G. D. Stucky, X. Ji, Nano Lett. 2014, 14, 4119.

[35] C. Wang, Y. Fang, Y. Xu, L. Liang, M. Zhou, H. Zhao, Y. Lei, Adv. Funct. Mater. 2015, doi: 10.1002/adfm.201504537.

[36] P. G. Bruce, B. Scrosati, J. M. Tarascon, Angew. Chem. Int. Ed. 2008, 47, 2930.

[37] M. G. Kim, J. Cho, Adv. Funct. Mater. 2009, 19, 1497.

[38] C. Masquelier, L. Croguennec, Chem. Rev. 2013, 113, 6552.

[39] L. Croguennec, M. R. Palacin, J. Am. Chem. Soc. 2015, 137, 3140.

[40] S. W. Kim, D. H. Seo, X. Ma, G. Ceder, K. Kang, Adv. Energy Mater. 2012, 2, 710.

[41] M. D. Slater, D. Kim, E. Lee, C. S. Johnson, Adv. Funct. Mater. 2013, 23, 947.

[42] N. Yabuuchi, K. Kubota, M. Dahbi, S. Komaba, Chem. Rev. 2014, 114, 11636.

[43] H. Pan, Y.-S. Hu, L. Chen, Energy Environ. Sci. 2013, 6, 2338.

[44] V. Palomares, P. Serras, I. Villaluenga, K. B. Hueso, J. Carretero-González, T. Rojo, Energy Environ. Sci. 2012, 5, 5884.

[45] H. Zhao, M. Zhou, L. Wen, Y. Lei, Nano Energy 2015, 13, 790.

[46] L. Wen, Z. Wang, Y. Mi, R. Xu, S. H. Yu, Y. Lei, Small 2015, 11, 3408.

[47] Z. Wang, D. Cao, R. Xu, S. Qu, Z. Wang, Y. Lei, Nano Energy, 2016, 19, 328.

[48] D. R. Rolison, J. W. Long, J. C. Lytle, A. E. Fischer, C. P. Rhodes, T. M. McEvoy, M. E. Bourg, A. M. Lubers, Energy Environ. Sci. 2009, 38, 226.

[49] F.-F. Cao, Y.-G. Guo, L.-J. Wan, Energy Environ. Sci. 2011, 4, 1634. 


\section{WILEY-VCH}

[50] L. Su, Y. Jing, Z. Zhou, Nanoscale 2011, 3, 3967.

[51] L. Hu, Q. Chen, Nanoscale 2014, 6, 1236.

[52] C. Zhu, P. Yang, D. Chao, W. Mai, H. J. Fan, ChemNanoMat 2015, 1, 458.

[53] A. Manthiram, J. Phys. Chem. Lett. 2011, 2, 176.

[54] J. B. Goodenough, K.-S. Park, J. Am. Chem. Soc. 2013, 135, 1167.

[55] M. Winter, R. J. Brodd, Chem. Rev. 2004, 104, 4245.

[56] K. M. Abraham, J. Phys. Chem. Lett. 2015, 6, 830.

[57] Z. L. Wang, J. Song, Science 2006, 312, 242.

[58] S. W. Boettcher, J. M. Spurgeon, M. C. Putnam, E. L. Warren, D. B. Turner-Evans, M.

D. Kelzenberg, J. R. Maiolo, H. A. Atwater, N. S. Lewis, Science 2010, 327, 185.

[59] P. Banerjee, I. Perez, L. Henn-Lecordier, S. B. Lee, G. W. Rubloff, Nat. Nanotechnol. 2009, 4, 292.

[60] W.-Q. Wu, H.-L. Feng, H.-S. Rao, Y.-F. Xu, D.-B. Kuang, C.-Y. Su, Nat. Commun. 2014, 5, 3968 .

[61] C. K. Chan, H. Peng, G. Liu, K. McIlwrath, X. F. Zhang, R. A. Huggins, Y. Cui, Nat. Nanotechnol. 2008, 3, 31 .

[62] A. Kohandehghan, P. Kalisvaart, M. Kupsta, B. Zahiri, B. S. Amirkhiz, Z. Li, E. L. Memarzadeh, L. A. Bendersky, D. Mitlin, J. Mater. Chem. A 2013, 1, 1600.

[63] E. L. Memarzadeh, W. P. Kalisvaart, A. Kohandehghan, B. Zahiri, C. M. Holt, D. Mitlin, J. Mater. Chem. 2012, 22, 6655.

[64] X. Li, J. H. Cho, N. Li, Y. Zhang, D. Williams, S. A. Dayeh, S. Picraux, Adv. Energy Mater. 2012, 2, 87.

[65] S. Jing, H. Jiang, Y. Hu, C. Li, Nanoscale 2014, 6, 14441.

[66] B. Farbod, K. Cui, M. Kupsta, W. P. Kalisvaart, E. Memarzadeh, A. Kohandehghan, B. Zahiri, D. Mitlin, J. Mater. Chem. A 2014, 2, 16770. 


\section{WILEY-VCH}

[67] T. Song, H. Cheng, K. Town, H. Park, R. W. Black, S. Lee, W. I. Park, Y. Huang, J. A. Rogers, L. F. Nazar, Adv. Funct. Mater. 2014, 24, 1458.

[68] A. Gohier, B. Laïk, K. H. Kim, J. L. Maurice, J. P. Pereira - Ramos, C. S. Cojocaru, P. T. Van, Adv. Mater. 2012, 24, 2592.

[69] X. Wang, R. A. Susantyoko, Y. Fan, L. Sun, Q. Xiao, Q. Zhang, Small 2014, 10, 2826.

[70] F. Lou, H. Zhou, T. D. Tran, M. E. Melandsø Buan, F. Vullum - Bruer, M. Rønning, J. C. Walmsley, D. Chen, ChemSusChem 2014, 7, 1335.

[71] S. Lee, J. Ha, H. Cheng, J. W. Lee, T. S. Jang, Y. G. Jung, Y. Huang, J. A. Rogers, U. Paik, Adv. Energy Mater. 2014, 4, 1300472.

[72] H. Zhou, F. Lou, P. E. Vullum, M.-A. Einarsrud, D. Chen, F. Vullum-Bruer, Nanotechnology 2013, 24, 435703.

[73] H. Kim, X. Huang, X. Guo, Z. Wen, S. Cui, J. Chen, ACS Appl. Mater. Interfaces 2014, 6, 18590.

[74] G. P. Pandey, S. A. Klankowski, Y. Li, X. S. Sun, J. Wu, R. A. Rojeski, J. Li, ACS Appl. Mater. Interfaces 2015, 7, 20909.

[75] S. Moitzheim, C. Nimisha, S. Deng, D. J. Cott, C. Detavernier, P. Vereecken, Nanotechnology 2014, 25, 504008.

[76] R. Thomas, K. Y. Rao, G. M. Rao, Electrochimica Acta 2013, 108, 458.

[77] H. Kim, Z. Wen, K. Yu, O. Mao, J. Chen, J. Mater. Chem. 2012, 22, 15514.

[78] P. Meduri, E. Clark, J. H. Kim, E. Dayalan, G. U. Sumanasekera, M. K. Sunkara, Nano Lett. 2012, 12, 1784.

[79] W. Zhou, C. Cheng, J. Liu, Y. Y. Tay, J. Jiang, X. Jia, J. Zhang, H. Gong, H. H. Hng, T. Yu, Adv. Funct. Mater. 2011, 21, 2439.

[80] W. Ren, C. Wang, L. Lu, D. Li, C. Cheng, J. Liu, J. Mater. Chem. A 2013, 1, 13433. 


\section{WILEY-VCH}

[81] D. H. Sim, X. Rui, J. Chen, H. Tan, T. M. Lim, R. Yazami, H. H. Hng, Q. Yan, RSC $A d v . \mathbf{2 0 1 2}, 2,3630$.

[82] F. Li, H. Yue, P. Wang, Z. Yang, D. Wang, D. Liu, L. Qiao, D. He, CrystEngComm 2013, 15,7298 .

[83] Q. Zhang, H. Chen, J. Wang, D. Xu, X. Li, Y. Yang, K. Zhang, ChemSusChem 2014, $7,2325$.

[84] H. T. Nguyen, M. R. Zamfir, L. D. Duong, Y. H. Lee, P. Bondavalli, D. Pribat, J. Mater. Chem. 2012, 22, 24618.

[85] X. Fan, H. Zhang, N. Du, P. Wu, X. Xu, Y. Li, D. Yang, Nanoscale 2012, 4, 5343.

[86] K. Cheng, F. Yang, K. Ye, Y. Zhang, X. Jiang, J. Yin, G. Wang, D. Cao, J. Power Sources 2014, 258, 260.

[87] P. R. Abel, Y.-M. Lin, T. de Souza, C.-Y. Chou, A. Gupta, J. B. Goodenough, G. S. Hwang, A. Heller, C. B. Mullins, J. Phys. Chem. C 2013, 117, 18885.

[88] P. R. Abel, A. M. Chockla, Y.-M. Lin, V. C. Holmberg, J. T. Harris, B. A. Korgel, A. Heller, C. B. Mullins, ACS Nano 2013, 7, 2249.

[89] K.-X. Wang, Y. Li, X.-Y. Wu, J.-S. Chen, J. Power Sources 2012, 203, 140.

[90] B. Polat, O. Keles, K. Amine, Nano Lett. 2015, 15, 6702.

[91] Y. He, B. Yang, K. Yang, C. Brown, R. Ramasamy, H. Wang, C. Lundgren, Y. Zhao, J. Mater. Chem. 2012, 22, 8294.

[92] Y. Yang, Y. He, Y. Zhao, X. Li, J. Appl. Phys. 2012, 112, 103502.

[93] C. Wang, L. Wu, H. Wang, W. Zuo, Y. Li, J. Liu, Adv. Funct. Mater. 2015, 25, 3524.

[94] Y. Luo, J. Luo, J. Jiang, W. Zhou, H. Yang, X. Qi, H. Zhang, H. J. Fan, Y. Denis, C. M. Li, Energy Environ. Sci. 2012, 5, 6559.

[95] Y. Liu, C. Liu, J. Li, J. Mater. Chem. A 2014, 2, 15746.

[96] L. Gao, S. Li, D. Huang, Y. Shen, M. Wang, J. Mater. Chem. A 2015, 3, 10107.

[97] L. Peng, H. Zhang, Y. Bai, Y. Zhang, Y. Wang, Nanoscale 2015, 7, 8758. 


\section{WILEY-VCH}

[98] J.-Y. Liao, D. Higgins, G. Lui, V. Chabot, X. Xiao, Z. Chen, Nano Lett. 2013, 13, 5467.

[99] J. Y. Liao, A. Manthiram, Adv. Energy Mater. 2014, 4, 1400403.

[100] S. Chen, Y. Xin, Y. Zhou, F. Zhang, Y. Ma, H. Zhou, L. Qi, J. Mater. Chem. A 2015, $3,13377$.

[101] D. Lei, M. Zhang, B. Qu, L. Chen, Y. Wang, E. Zhang, Z. Xu, Q. Li, T. Wang, Nanoscale 2012, 4, 3422.

[102] Q.-q. Xiong, J.-p. Tu, X.-h. Xia, X.-y. Zhao, C.-d. Gu, X.-l. Wang, Nanoscale 2013, 5, 7906.

[103] J. Liu, Y. Li, X. Huang, R. Ding, Y. Hu, J. Jiang, L. Liao, J. Mater. Chem. 2009, 19, 1859.

[104] L. Zhang, H. B. Wu, X. D. W. Lou, Mater. Horiz. 2014, 1, 133.

[105] W. Xu, K. Zhao, C. Niu, L. Zhang, Z. Cai, C. Han, L. He, T. Shen, M. Yan, L. Qu, Nano Energy 2014, 8, 196.

[106] S. Chen, M. Wang, J. Ye, J. Cai, Y. Ma, H. Zhou, L. Qi, Nano Research 2013, 6, 243.

[107] L. Zhang, K. Zhao, W. Xu, Y. Dong, R. Xia, F. Liu, L. He, Q. Wei, M. Yan, L. Mai, Phys. Chem. Chem. Phys. 2015, 17, 7619.

[108] L. Gao, F. Qu, X. Wu, J. Mater. Chem. A 2014, 2, 7367.

[109] X. Li, D. Li, L. Qiao, X. Wang, X. Sun, P. Wang, D. He, J. Mater. Chem. 2012, 22, 9189.

[110] H. Wang, X. Gao, J. Feng, S. Xiong, Electrochimica Acta 2015, 182, 769.

[111] Y. Wang, H. J. Zhang, W. X. Lim, J. Y. Lin, C. C. Wong, J. Mater. Chem. 2011, 21, 2362.

[112] X. Xia, D. Chao, C. F. Ng, J. Lin, Z. Fan, H. Zhang, Z. X. Shen, H. J. Fan, Mater. Horiz. 2015, 2, 237.

[113] X. Yu, Z. Lu, G. Zhang, X. Lei, J. Liu, L. Wang, X. Sun, RSC Adv. 2013, 3, 19937. 


\section{WILEY-VCH}

[114] Y. Cao, D. Fang, C. Wang, L. Li, W. Xu, Z. Luo, X. Liu, C. Xiong, S. Liu, RSC Adv. $\mathbf{2 0 1 5}, 5,42955$.

[115] L. Shen, E. Uchaker, X. Zhang, G. Cao, Adv. Mater. 2012, 24, 6502.

[116] S. Chen, Y. Xin, Y. Zhou, Y. Ma, H. Zhou, L. Qi, Energy Environ. Sci. 2014, 7, 1924.

[117] J.-Y. Liao, V. Chabot, M. Gu, C. Wang, X. Xiao, Z. Chen, Nano Energy 2014, 9, 383.

[118] J. Jiang, J. Zhu, Y. Feng, J. Liu, X. Huang, Chem. Commun. 2012, 48, 7471.

[119] Y. Zhang, W. Zhang, M. Li, Z. Yang, G. Chen, Q. Wang, J. Mater. Chem. A 2013, 1, 14368.

[120] D. Li, X. Li, X. Hou, X. Sun, B. Liu, D. He, Chem. Commun. 2014, 50, 9361.

[121] H. Yu, C. Zhu, K. Zhang, Y. Chen, C. Li, P. Gao, P. Yang, Q. Ouyang, J. Mater. Chem. A 2014, 2, 4551.

[122] Y. Bai, H. Zhang, L. Fang, L. Liu, H. Qiu, Y. Wang, J. Mater. Chem. A 2015, 3, 5434.

[123] B. Li, Z. Cheng, N. Zhang, K. Sun, Nano Energy 2014, 4, 7.

[124] G. Z. Cynthia, Handbook of Electrochemistry, Elsevier, 2007.

[125] G. Zhang, S. Hou, H. Zhang, W. Zeng, F. Yan, C. C. Li, H. Duan, Adv. Mater. 2015, $27,2400$.

[126] S. Zhang, Z. Du, R. Lin, T. Jiang, G. Liu, X. Wu, D. Weng, Adv. Mater. 2010, 22, 5378.

[127] X. Wang, Z. Yang, X. Sun, X. Li, D. Wang, P. Wang, D. He, J. Mater. Chem. 2011, $21,9988$.

[128] Z. Du, S. Zhang, Y. Xing, X. Wu, J. Power Sources 2011, 196, 9780.

[129] J. Hao, X. Liu, X. Liu, X. Liu, N. Li, X. Ma, Y. Zhang, Y. Li, J. Zhao, RSC Adv. 2015, $5,19596$.

[130] Y. Tang, X. Xia, Y. Yu, S. Shi, J. Chen, Y. Zhang, J. Tu, Electrochimica Acta 2013, $88,664$.

[131] N. Wang, T. Hang, H. Ling, A. Hu, M. Li, J. Mater. Chem. A 2015, 3, 11912. 


\section{WILEY-VCH}

[132] F. Cao, X. Xia, G. Pan, J. Chen, Y. Zhang, Electrochimica Acta 2015, 178, 574.

[133] A. Xiao, S. Zhou, C. Zuo, Y. Zhuan, X. Ding, Mater. Res. Bull. 2015, 70, 795.

[134] J. H. Shin, S. H. Park, S. M. Hyun, J. W. Kim, H. M. Park, J. Y. Song, Phys. Chem. Chem. Phys. 2014, 16, 18226.

[135] C.-H. Lai, K.-W. Huang, J.-H. Cheng, C.-Y. Lee, W.-F. Lee, C.-T. Huang, B.-J. Hwang, L.-J. Chen, J. Mater. Chem. 2009, 19, 7277.

[136] C.-H. Lai, K.-W. Huang, J.-H. Cheng, C.-Y. Lee, B.-J. Hwang, L.-J. Chen, J. Mater. Chem. 2010, 20, 6638.

[137] S. Liu, X. Yin, Q. Hao, M. Zhang, L. Li, L. Chen, Q. Li, Y. Wang, T. Wang, Mater. Lett. 2010, 64, 2350.

[138] C. Wang, W. Wan, Y. Huang, J. Chen, H. H. Zhou, X. X. Zhang, Nanoscale 2014, 6, 5351.

[139] Y. Li, B. Tan, Y. Wu, Nano Lett. 2008, 8, 265.

[140] Q. Xiong, X. Xia, J. Tu, J. Chen, Y. Zhang, D. Zhou, C. Gu, X. Wang, J. Power Sources 2013, 240, 344.

[141] C. W. Lee, S.-D. Seo, D. W. Kim, S. Park, K. Jin, D.-W. Kim, K. S. Hong, Nano Research 2013, 6, 348.

[142] Y. Mai, J. Tu, X. Xia, C. Gu, X. Wang, J. Power Sources 2011, 196, 6388.

[143] Q. Chen, B. Heng, H. Wang, D. Sun, B. Wang, M. Sun, S. Guan, R. Fu, Y. Tang, J. Alloy. Compd. 2015, 641, 80.

[144] F. F. Cao, J. W. Deng, S. Xin, H. X. Ji, O. G. Schmidt, L. J. Wan, Y. G. Guo, Adv. Mater. 2011, 23, 4415.

[145] B. Varghese, M. Reddy, Z. Yanwu, C. S. Lit, T. C. Hoong, G. Subba Rao, B. Chowdari, A. T. S. Wee, C. T. Lim, C.-H. Sow, Chem. Mater. 2008, 20, 3360.

[146] M. Qiu, L. Yang, X. Qi, J. Li, J. Zhong, ACS Appl. Mater. Interfaces 2010, 2, 3614.

[147] R. Huang, X. Fan, W. Shen, J. Zhu, Appl. Phys. Lett. 2009, 95, 133119. 


\section{WILEY-VCH}

[148] L. Sun, X. Wang, R. A. Susantyoko, Q. Zhang, J. Mater. Chem. A 2014, 2, 15294.

[149] Z. Huang, N. Geyer, P. Werner, J. De Boor, U. Gösele, Adv. Mater. 2011, 23, 285.

[150] Y. Liu, Y. Qiao, W. Zhang, P. Hu, C. Chen, Z. Li, L. Yuan, X. Hu, Y. Huang, J. Alloy. Compd. 2014, 586, 208.

[151] W. Zhang, G. Ma, H. Gu, Z. Yang, H. Cheng, J. Power Sources 2015, 273, 561.

[152] J. R. González, R. Alcántara, G. F. Ortiz, F. Nacimiento, J. L. Tirado, J. Electrochem. Soc. 2013, 160, A1390.

[153] Z. Bi, M. P. Paranthaman, P. A. Menchhofer, R. R. Dehoff, C. A. Bridges, M. Chi, B. Guo, X.-G. Sun, S. Dai, J. Power Sources 2013, 222, 461.

[154] L. Z. Fan, S. S. Chi, L. N. Wang, W. L. Song, M. He, L. Gu, ChemElectroChem 2015, 2,421 .

[155] A. Lamberti, N. Garino, A. Sacco, S. Bianco, A. Chiodoni, C. Gerbaldi, Electrochimica Acta 2015, 151, 222.

[156] D. Pan, H. Huang, X. Wang, L. Wang, H. Liao, Z. Li, M. Wu, J. Mater. Chem. A 2014, 2,11454 .

[157] Q. L. Wu, J. Li, R. D. Deshpande, N. Subramanian, S. E. Rankin, F. Yang, Y.-T. Cheng, J. Phys. Chem. C 2012, 116, 18669.

[158] H. Li, S. K. Martha, R. R. Unocic, H. Luo, S. Dai, J. Qu, J. Power Sources 2012, 218, 88.

[159] M. Madian, L. Giebeler, M. Klose, T. Jaumann, M. Uhlemann, A. Gebert, S. Oswald, N. Ismail, A. Eychmüller, J. Eckert, ACS Sustainable Chem. Eng. 2015, 3, 909.

[160] T. Yiping, T. Xiaoxu, H. Guangya, Z. Guoqu, Electrochimica Acta 2014, 117, 172.

[161] L. Xue, Z. Wei, R. Li, J. Liu, T. Huang, A. Yu, J. Mater. Chem. 2011, 21, 3216.

[162] L. Yu, Z. Wang, L. Zhang, H. B. Wu, X. W. D. Lou, J. Mater. Chem. A 2013, 1, 122.

[163] J. Rong, X. Fang, M. Ge, H. Chen, J. Xu, C. Zhou, Nano Research 2013, 6, 182.

[164] D. Guan, J. Li, X. Gao, C. Yuan, RSC Adv. 2014, 4, 4055. 


\section{WILEY-VCH}

[165] W. Yang, G. Cheng, C. Dong, Q. Bai, X. Chen, Z. Peng, Z. Zhang, J. Mater. Chem. A 2014, 2, 20022.

[166] S. Saadat, J. Zhu, D. H. Sim, H. H. Hng, R. Yazami, Q. Yan, J. Mater. Chem. A 2013, 1,8672 .

[167] E. Quiroga-González, E. Ossei-Wusu, J. Carstensen, H. Föll, J. Electrochem. Soc. 2011, 158, E119.

[168] Y. Yu, C. Yue, S. Sun, W. Lin, H. Su, B. Xu, J. Li, S. Wu, J. Li, J. Kang, ACS Appl. Mater. Interfaces 2014, 6, 5884.

[169] M. S. Jung, J. H. Seo, M. W. Moon, J. W. Choi, Y. C. Joo, I. S. Choi, Adv. Energy Mater. 2015, 5, 1400611.

[170] H. Masuda, K. Fukuda, Science 1995, 268, 1466.

[171] W. Lee, S.-J. Park, Chem. Rev. 2014, 114, 7487.

[172] Y. Lei, W. Cai, G. Wilde, Prog. Mater. Sci. 2007, 52, 465.

[173] Y. Lei, S. Yang, M. Wu, G. Wilde, Chem. Soc. Rev. 2011, 40, 1247.

[174] J. Lee, S. Mubeen, X. Ji, G. D. Stucky, M. Moskovits, Nano Lett. 2012, 12, 5014.

[175] X. Wang, C. Liow, D. Qi, B. Zhu, W. R. Leow, H. Wang, C. Xue, X. Chen, S. Li, Adv. Mater. 2014, 26, 3506.

[176] A. Al-Haddad, Z. Zhan, C. Wang, S. Tarish, R. Vellacheri, Y. Lei, ACS Nano 2015, 9, 8584.

[177] Z. Zhan, F. Grote, Z. Wang, R. Xu, Y. Lei, Adv. Energy Mater. 2015, doi: 10.1002/aenm.201501654.

[178] F. Grote, Y. Lei, Nano Energy 2014, 10, 63.

[179] H. Masuda, H. Yamada, M. Satoh, H. Asoh, M. Nakao, T. Tamamura, Appl. Phys. Lett. 1997, 71, 2770.

[180] Q. Lin, B. Hua, S. Leung, X. Duan, Z. Fan, ACS Nano 2013, 7, 2725. 


\section{WILEY-VCH}

[181] Y. Qiu, S. Leung, Q. Zhang, B. Hua, Q. Lin, Z. Wei, K. Tsui, Y. Zhang, S. Yang, Z. Fan, Nano Lett. 2014, 14, 2123.

[182] H. Zhao, C. Wang, R. Vellacheri, M. Zhou, Y. Xu, Q. Fu, H. Wu, F. Grote, Y. Lei, Adv. Mater. 2014, 26, 7654

[183] Z. Zhan, Y. Lei, ACS Nano 2014, 8, 3862.

[184] Z. Zhan, R. Xu, Y. Mi, H. Zhao, Y. Lei, ACS Nano 2015, 9, 4583.

[185] C. R. Martin, Science 1994, 266, 1961.

[186] C. R. Martin, Acc. Chem. Res. 1995, 28, 61.

[187] C. R. Martin, Chem. Mater. 1996, 8, 1739.

[188] Y. Lee, I. Leu, C. Liao, S. Chang, M. Wu, J. Yen, K. Fung, Electrochem. Solid-State Lett. 2006, 9, A207.

[189] J.-H. Kim, T. Ayalasomayajula, V. Gona, D. Choi, J. Power Sources 2008, 183, 366.

[190] X. Fan, P. Dou, A. Jiang, D. Ma, X. Xu, ACS Appl. Mater. Interfaces 2014, 6, 22282.

[191] X. Liu, J. Hao, X. Liu, C. Chi, N. Li, F. Endres, Y. Zhang, Y. Li, J. Zhao, Chem. Commun. 2015, 51, 2064.

[192] G. Ferrara, L. Damen, C. Arbizzani, R. Inguanta, S. Piazza, C. Sunseri, M. Mastragostino, J. Power Sources 2011, 196, 1469.

[193] J. Hassoun, S. Panero, P. Simon, P. L. Taberna, B. Scrosati, Adv. Mater. 2007, 19, 1632.

[194] H. Guan, X. Wang, S. Chen, Y. Bando, D. Golberg, Chem. Commun. 2011, 47, 12098.

[195] J. Wang, N. Du, H. Zhang, J. Yu, D. Yang, J. Mater. Chem. 2012, 22, 1511.

[196] M. Valvo, D. Rehnlund, U. Lafont, M. Hahlin, K. Edström, L. Nyholm, J. Mater. Chem. A 2014, 2, 9574.

[197] J. Wang, N. Du, H. Zhang, J. Yu, D. Yang, J. Power Sources 2012, 208, 434.

[198] J. Qu, H. Li, J. J. Henry, S. K. Martha, N. J. Dudney, H. Xu, M. Chi, M. J. Lance, S. M. Mahurin, T. M. Besmann, J. Power Sources 2012, 198, 312. 


\section{WILEY-VCH}

[199] M. M. Shaijumon, E. Perre, B. Daffos, P. L. Taberna, J. M. Tarascon, P. Simon, Adv. Mater. 2010, 22, 4978.

[200] S. K. Cheah, E. Perre, M. Rooth, M. Fondell, A. Hårsta, L. Nyholm, M. Boman, T. r. Gustafsson, J. Lu, P. Simon, Nano Lett. 2009, 9, 3230.

[201] H. Liu, Q. Li, ACS Appl. Mater. Interfaces 2013, 5, 12190.

[202] W. Wang, M. Tian, A. Abdulagatov, S. M. George, Y.-C. Lee, R. Yang, Nano Lett. 2012, 12,655 .

[203] J. J. Schneider, J. Khanderi, A. Popp, J. Engstler, H. Tempel, A. Sarapulova, N. N. Bramnik, D. Mikhailova, H. Ehrenberg, L. A. Schmitt, Eur. J. Inorg. Chem. 2011, 4349.

[204] C. Zhao, Q. Li, W. Wan, J. Li, J. Li, H. Zhou, D. Xu, J. Mater. Chem. 2012, 22, 12193.

[205] M. Kim, J. Lee, S. Lee, S. Seo, C. Bae, H. Shin, ChemSusChem 2015, 8, $2363 .$.

[206] A. T. Tesfaye, R. Gonzalez, J. L. Coffer, T. Djenizian, ACS Appl. Mater. Interfaces 2015, 7, 20495.

[207] Z. Lu, T. Wong, T.-W. Ng, C. Wang, RSC Adv. 2014, 4, 2440.

[208] T. Song, H. Cheng, H. Choi, J.-H. Lee, H. Han, D. H. Lee, D. S. Yoo, M.-S. Kwon, J.M. Choi, S. G. Doo, ACS Nano 2011, 6, 303.

[209] J. Liu, N. Li, M. D. Goodman, H. G. Zhang, E. S. Epstein, B. Huang, Z. Pan, J. Kim, J. H. Choi, X. Huang, ACS Nano 2015, 9, 1985.

[210] J. Liu, K. Song, P. A. van Aken, J. Maier, Y. Yu, Nano Lett. 2014, 14, 2597.

[211] J. Wang, N. Du, H. Zhang, J. Yu, D. Yang, J. Phys. Chem. C 2011, 115, 11302.

[212] W. Zeng, F. Zheng, R. Li, Y. Zhan, Y. Li, J. Liu, Nanoscale 2012, 4, 2760.

[213] F. Xia, S. B. Kim, H. Cheng, J. M. Lee, T. Song, Y. Huang, J. A. Rogers, U. Paik, W. I. Park, Nano Lett. 2013, 13, 3340.

[214] Y. Wang, H. Xia, L. Lu, J. Lin, ACS Nano 2010, 4, 1425.

[215] X.-Y. Xue, S. Yuan, L.-L. Xing, Z.-H. Chen, B. He, Y.-J. Chen, Chem. Commun. 2011, $47,4718$. 


\section{WILEY-VCH}

[216] L. Yu, L. Zhang, H. B. Wu, G. Zhang, X. W. D. Lou, Energy Environ. Sci. 2013, 6, 2664.

[217] L. Zhan, S. Wang, L.-X. Ding, Z. Li, H. Wang, J. Mater. Chem. A 2015, 3, 19711.

[218] J. Jiang, J. Liu, R. Ding, X. Ji, Y. Hu, X. Li, A. Hu, F. Wu, Z. Zhu, X. Huang, J. Phys. Chem. C 2009, 114, 929.

[219] X. Wang, Y. Fan, R. A. Susantyoko, Q. Xiao, L. Sun, D. He, Q. Zhang, Nano Energy 2014, 5, 91.

[220] J. Wang, Q. Zhang, X. Li, D. Xu, Z. Wang, H. Guo, K. Zhang, Nano Energy 2014, 6, 19.

[221] J. Jiang, J. Luo, J. Zhu, X. Huang, J. Liu, T. Yu, Nanoscale 2013, 5, 8105.

[222] X. Yan, X. Tong, J. Wang, C. Gong, M. Zhang, L. Liang, J. Alloy. Compd. 2013, 556, 56.

[223] X. Wang, L. Qiao, X. Sun, X. Li, D. Hu, Q. Zhang, D. He, J. Mater. Chem. A 2013, 1, 4173.

[224] F. Cao, G. Pan, P. Tang, H. Chen, Mater. Res. Bull. 2013, 48, 1178.

[225] J. Liu, C. Liu, Y. Wan, W. Liu, Z. Ma, S. Ji, J. Wang, Y. Zhou, P. Hodgson, Y. Li, CrystEngComm 2013, 15, 1578.

[226] Y. Chen, J. Zhu, B. Qu, B. Lu, Z. Xu, Nano Energy 2014, 3, 88.

[227] J. Cheng, Y. Lu, K. Qiu, H. Yan, J. Xu, L. Han, X. Liu, J. Luo, J.-K. Kim, Y. Luo, Sci. Rep. 2015, 5, 12099.

[228] Z. Sun, W. Ai, J. Liu, X. Qi, Y. Wang, J. Zhu, H. Zhang, T. Yu, Nanoscale 2014, 6, 6563.

[229] B. Liu, J. Zhang, X. Wang, G. Chen, D. Chen, C. Zhou, G. Shen, Nano Lett. 2012, 12, 3005 .

[230] Q. Li, X. Miao, C. Wang, L. Yin, J. Mater. Chem. A 2015, 3, 21328.

[231] Y. Feng, R. Zou, D. Xia, L. Liu, X. Wang, J. Mater. Chem. A 2013, 1, 9654. 


\section{WILEY-VCH}

[232] M. Zhou, H. B. Wu, J. Bao, L. Liang, X. W. D. Lou, Y. Xie, Angew. Chem. Int. Ed. 2013, 52, 8579 .

[233] M. Zhou, J. Bao, Y. Xu, J. Zhang, J. Xie, M. Guan, C. Wang, L. Wen, Y. Lei, Y. Xie, ACS Nano 2014, 8, 7088 .

[234] S. Yang, W. Cai, L. Kong, Y. Lei, Adv. Funct. Mater. 2010, 20, 2527.

[235] S. Yang, Y. Lei, Nanoscale 2011, 3, 2768.

[236] S. Yang, F. Xu, S. Ostendorp, G. Wilde, H. Zhao, Y. Lei, Adv. Funct. Mater. 2011, 21, 2446.

[237] J. C. Lytle, H. Yan, N. S. Ergang, W. H. Smyrl, A. Stein, J. Mater. Chem. 2004, 14, 1616.

[238] N. S. Ergang, J. C. Lytle, K. T. Lee, S. M. Oh, W. H. Smyrl, A. Stein, Adv. Mater. 2006, $18,1750$.

[239] J. S. Sakamoto, B. Dunn, J. Mater. Chem. 2002, 12, 2859.

[240] H. Zhang, X. Yu, P. V. Braun, Nat. Nanotechnol. 2011, 6, 277.

[241] K. Cao, L. Jiao, Y. Liu, H. Liu, Y. Wang, H. Yuan, Adv. Funct. Mater. 2015, 25, 1082.

[242] S. R. Gowda, A. Leela Mohana Reddy, X. Zhan, P. M. Ajayan, Nano Lett. 2011, 11, 3329.

[243] G. Chen, J. Yang, J. Tang, X. Zhou, RSC Adv. 2015, 5, 23067.

[244] Y. Cao, D. Fang, R. Liu, M. Jiang, H. Zhang, G. Li, Z. Luo, X. Liu, J. Xu, W. Xu, C. Xiong, ACS Appl. Mater. Interfaces 2015, 7, 27685.

[245] X. Zhou, G. Chen, J. Tang, Y. Ren, J. Yang, J. Power Sources 2015, 299, 97.

[246] S. Soleimani-Amiri, S. A. S. Tali, S. Azimi, Z. Sanaee, S. Mohajerzadeh, Appl. Phys. Lett. 2014, 105, 193903.

[247] S. Peng, L. Yu, M. Sun, G. Cheng, T. Lin, Y. Mo, Z. Li, J. Power Sources 2015, 296, 237. 


\section{WILEY-VCH}

[248] L. Liu, H. Zhang, Y. Mu, J. Yang, Y. Wang, ACS Appl. Mater. Interfaces 2015, DOI: 10.1021/acsami.5b10237.

[249] J. Ha, U. Paik, J. Power Sources 2013, 244, 463.

[250] Y. Zhong, H. Fan, L. Chang, H. Shao, J. Wang, J. Zhang, C. Cao, J. Power Sources 2015, 296, 255.

[251] K. Cao, L. Jiao, H. Liu, Y. Liu, Y. Wang, Z. Guo, H. Yuan, Adv. Energy Mater. 2015, $5,1401421$.

[252] M. Chen, X. Xia, M. Qi, J. Yuan, J. Yin, Q. Chen, Electrochimica Acta 2015, 184, 17.

[253] R. Zou, Z. Zhang, M. F. Yuen, M. Sun, J. Hu, C.-S. Lee, W. Zhang, NPG Asia Mater. 2015, 7, e195.

[254] D. Li, L.-X. Ding, S. Wang, D. Cai, H. Wang, J. Mater. Chem. A 2014, 2, 5625.

[255] X. Wang, L. Sun, X. Hu, R. A. Susantyoko, Q. Zhang, J. Power Sources 2015, 280, 393.

[256] J. Wang, B. Gao, L. Zhang, R. Li, J. Shen, Z. Qiao, G. Yang, F. Nie, RSC Adv. 2014, 4, 30573.

[257] H. Wu, M. Xu, H. Wu, J. Xu, Y. Wang, Z. Peng, G. Zheng, J. Mater. Chem. 2012, 22, 19821.

[258] J. Jiang, J. Zhu, R. Ding, Y. Li, F. Wu, J. Liu, X. Huang, J. Mater. Chem. 2011, 21, 15969.

[259] W. Zhao, N. Du, C. Xiao, H. Wu, H. Zhang, D. Yang, J. Mater. Chem. A 2014, 2, 13949.

[260] X. Hou, X. Wang, B. Liu, Q. Wang, T. Luo, D. Chen, G. Shen, Nanoscale 2014, 6, 8858.

[261] G. Pan, X. Xia, F. Cao, J. Chen, Y. Zhang, J. Power Sources 2015, 293, 585.

[262] C. Zhu, X. Xia, J. Liu, Z. Fan, D. Chao, H. Zhang, H. J. Fan, Nano Energy 2014, 4, 105. 


\section{WILEY-VCH}

[263] X. Xia, Q. Xiong, Y. Zhang, J. Tu, C. F. Ng, H. J. Fan, Small 2014, 10, 2419.

[264] H. Chen, Q. Zhang, J. Wang, D. Xu, X. Li, Y. Yang, K. Zhang, J. Mater. Chem. A 2014, 2,8483 .

[265] W. Zhang, X. Yan, X. Tong, J. Yang, L. Miao, Y. Sun, L. Peng, Mater. Lett. 2016, 162, 101.

[266] T. Song, J. Xia, J.-H. Lee, D. H. Lee, M.-S. Kwon, J.-M. Choi, J. Wu, S. K. Doo, H. Chang, W. I. Park, D. S. Zang, H. Kim, Y. Huang, K.-C. Hwang, J. A. Rogers, U. Paik, Nano Lett. 2010, 10, 1710.

[267] H. Han, T. Song, E.-K. Lee, A. Devadoss, Y. Jeon, J. Ha, Y.-C. Chung, Y.-M. Choi, Y.-G. Jung, U. Paik, ACS Nano 2012, 6, 8308.

[268] Y. Chen, B. Qu, L. Hu, Z. Xu, Q. Li, T. Wang, Nanoscale 2013, 5, 9812.

[269] C. Liu, E. I. Gillette, X. Chen, A. J. Pearse, A. C. Kozen, M. A. Schroeder, K. E. Gregorczyk, S. B. Lee, G. W. Rubloff, Nat. Nanotechnol. 2014, 9, 1031.

[270] P.-L. Taberna, S. Mitra, P. Poizot, P. Simon, J.-M. Tarascon, Nat. Mater. 2006, 5, 567.

[271] S. Zhou, X. Yang, Y. Lin, J. Xie, D. Wang, ACS Nano 2011, 6, 919.

[272] X. Meng, D. Deng, ACS Appl. Mater. Interfaces 2015, 7, 6867.

[273] G. Zhao, C. Li, L. Zhang, J. Lv, Y. Niu, Y. Du, K. Sun, J. Mater. Chem. A 2015, 3, 22547.

[274] G. Kim, S. Jeong, J.-H. Shin, J. Cho, H. Lee, ACS Nano 2014, 8, 1907.

[275] F.-S. Ke, L. Huang, B. C. Solomon, G.-Z. Wei, L.-J. Xue, B. Zhang, J.-T. Li, X.-D. Zhou, S.-G. Sun, J. Mater. Chem. 2012, 22, 17511.

[276] H. Wu, N. Du, H. Zhang, D. Yang, J. Mater. Chem. A 2014, 2, 20510.

[277] J. Wang, N. Du, H. Zhang, J. Yu, D. Yang, J. Phys. Chem. C 2011, 115, 23620.

[278] T. Hang, D. Mukoyama, H. Nara, T. Yokoshima, T. Momma, M. Li, T. Osaka, J. Power Sources 2014, 256, 226. 


\section{WILEY-VCH}

[279] B. Han, S. Zhang, R. Zhou, X. Wu, X. Wei, Y. Xing, S. Wang, T. Qi, RSC Adv. 2014, $4,50752$.

[280] K. Gerasopoulos, X. Chen, J. Culver, C. Wang, R. Ghodssi, Chem. Commun. 2010, 46, 7349.

[281] Z. Du, S. Zhang, J. Phys. Chem. C 2011, 115, 23603.

[282] H. Liu, L. Hu, Y. S. Meng, Q. Li, Nanoscale 2013, 5, 10376.

[283] Y. Liu, W. Zhang, Y. Zhu, Y. Luo, Y. Xu, A. Brown, J. N. Culver, C. A. Lundgren, K. Xu, Y. Wang, C. Wang, Nano Lett. 2012, 13, 293.

[284] S. Liu, J. Feng, X. Bian, J. Liu, H. Xu, RSC Adv. 2015, 5, 60870.

[285] K. Xie, Z. Lu, H. Huang, W. Lu, Y. Lai, J. Li, L. Zhou, Y. Liu, J. Mater. Chem. 2012, $22,5560$.

[286] S. A. Klankowski, R. A. Rojeski, B. A. Cruden, J. Liu, J. Wu, J. Li, J. Mater. Chem. A 2013, 1,1055 .

[287] K. Fu, O. Yildiz, H. Bhanushali, Y. Wang, K. Stano, L. Xue, X. Zhang, P. D. Bradford, Adv. Mater. 2013, 25, 5109.

[288] J. Chen, X.-h. Xia, J.-p. Tu, Q.-q. Xiong, Y.-X. Yu, X.-1. Wang, C.-d. Gu, J. Mater. Chem. 2012, 22, 15056.

[288] W. Deng, X. Chen, Z. Liu, A. Hu, Q. Tang, Z. Li, Y. Xiong, J. Power Sources 2015, 277, 131.

[290] Y. Fan, Q. Zhang, C. Lu, Q. Xiao, X. Wang, B. kang Tay, Nanoscale 2013, 5, 1503.

[291] A. L. M. Reddy, M. M. Shaijumon, S. R. Gowda, P. M. Ajayan, Nano Lett. 2009, 9, 1002.

[292] Y. Wu, Y. Wei, J. Wang, K. Jiang, S. Fan, Nano Lett. 2013, 13, 818.

[293] A. Goyal, A. L. Reddy, P. M. Ajayan, Small 2011, 7, 1709.

[294] R. Li, Y. Wang, C. Zhou, C. Wang, X. Ba, Y. Li, X. Huang, J. Liu, Adv. Funct. Mater. 2015, 25, 5384. 


\section{WILEY-VCH}

[295] D. Chao, X. Xia, J. Liu, Z. Fan, C. F. Ng, J. Lin, H. Zhang, Z. X. Shen, H. J. Fan, Adv. Mater. 2014, 26, 5794.

[296] W. Zhang, Z. Zhou, W. Zhao, Z. Yang, X. Yang, J. Mater. Chem. A 2014, 2, 5800.

[297] J. Li, C. Yue, Y. Yu, Y.-S. Chui, J. Yin, Z. Wu, C. Wang, Y. Zang, W. Lin, J. Li, J. Mater. Chem. A 2013, 1, 14344.

[298] B. Wang, T. Qiu, X. Li, B. Luo, L. Hao, Y. Zhang, L. Zhi, J. Mater. Chem. A 2014, 3, 494.

[299] M.-S. Wu, H.-W. Chang, J. Phys. Chem. C 2013, 117, 2590.

[300] Y. Yang, X. Fan, G. Casillas, Z. Peng, G. Ruan, G. Wang, M. J. Yacaman, J. M. Tour, ACS Nano 2014, 8, 3939.

[301] L. Liang, Y. Xu, C. Wang, L. Wen, Y. Fang, Y. Mi, M. Zhou, H. Zhao, Y. Lei, Energy Environ. Sci. 2015, 8, 2954.

[302] X. Xie, K. Kretschmer, J. Zhang, B. Sun, D. Su, G. Wang, Nano Energy 2015, 13, 208.

[303] C. Yue, Y. Yu, S. Sun, X. He, B. Chen, W. Lin, B. Xu, M. Zheng, S. Wu, J. Li, Adv. Funct. Mater. 2015, 25, 1386.

[304] Y. Liu, Y. Xu, Y. Zhu, J. N. Culver, C. A. Lundgren, K. Xu, C. Wang, ACS Nano 2013, 7, 3627.

[305] S. Yuan, X. L. Huang, D. L. Ma, H. G. Wang, F. Z. Meng, X. B. Zhang, Adv. Mater. 2014, 26, 2273.

[306] Y. Mo, Q. Ru, J. Chen, X. Song, L. Guo, S. Hu, S. Peng, J. Mater. Chem. A 2015, 3, 19765.

[307] X. Wang, Y. Li, Y. Gao, Z. Wang, L. Chen, Nano Energy 2015, 13, 687.

[308] D. Chao, C. Zhu, X. Xia, J. Liu, X. Zhang, J. Wang, P. Liang, J. Lin, H. Zhang, Z. X. Shen, H. Fan, Nano Lett. 2014, 15, 565.

[309] Y. Xu, M. Zhou, L. Wen, C. Wang, H. Zhao, Y. Mi, L. Liang, Q. Fu, M. Wu, Y. Lei, Chem. Mater. 2015, 27, 4274. 


\section{WILEY-VCH}

[310] K. Xie, B. Wei, Adv. Mater. 2014, 26, 3592.

[311] J.-Y. Shin, T. Yamada, H. Yoshikawa, K. Awaga, H. Shinokubo, Angew. Chem. Int. Ed. 2014, 53, 3096.

[312] Y. Liang, Z. Chen, Y. Jing, Y. Rong, A. Facchetti, Y. Yao, J. Am. Chem. Soc. 2015, $137,4956$.

[313] M. L.-Herraiz, E. C.-Martinez, J. C.-Gonzalez, J. Carrasco, T. Rojo, M. Armad, Energy Environ. Sci. 2015, 8, 3233.

[314] S. Wang, L. Wang, Z. Zhu, Z. Hu, Q. Zhao, J. Chen, Angew. Chem. Int. Ed. 2014, 126, 6002.

[315] A. Abouimrane, W. Wenig, H. Eltayeb, Y. Cui, J. Niklas, O. Poluektov, K. Amine, Energy Environ. Sci. 2012, 5, 9632.

[316] S. Wang, L. Wang, K. Zhang, Z. Zhu, Z. Tao, J. Chen, Nano Lett. 2013, 13, 4404.

[317] C. Luo, J. Wang, X. Fan, Y. Zhu, F. Han, L. Suo, C. Wang, Nano Energy 2015, 13, 537.

[318] F. Wan, X. Wu, J. Guo, J. Li, J. Zhang, L. Niu, R. Wang, Nano Energy 2015, 13, 450.

[319] Y. Sun, L. Zhao, H. Pan, X. Lu, L. Gu, Y. Hu, H. Li, M. Armad, Y. Ikuhara, L. Chen, X. Huang, Nature. Commun. 2013, 4, 1870.

[320] Y. Hu, Z. Liu, K. Nam, O. J. Borkiewicz, J. Cheng, X. Hua, M. T. Dunstan, X. Yu, K. M. Wiaderek, L. Du, K. W. Chapman, P. J. Chupas, X. Yang, C. P. Grey, Nature Mater. 2013, $12,1130$.

[321] D. J. Miller, C. Proff, J. G. Wen, D. P. Abraham, J. Bareno, Adv. Energy Mater. 2013, $3,1098$.

[322] R. Bhattacharyya, B. Key, H. Chen, A. S. Best, A. F. Hollenkamp, C. P. Grey, Nature Mater. 2010, 9, 504.

[323] M. S. Islam, C. A. Fisher, Chem. Soc. Rev. 2014, 43, 185.

[324] S. P. Ong, V. L. Chevrier, G. Hautier, A. Jain, C. Moore, S. Kim, X. Ma, G. Ceder, Energy Environ. Sci. 2011, 4, 3680. 


\section{WILEY-VCH}

[325] J. Muldoon, C. B. Bucur, T. Gregory, Chem. Rev. 2014, 114, 11683.

[326] S. Liu, J. Hu, N. Yan, G. Pan, G. Li, X. Gao, Energy Environ. Sci. 2012, 5, 9743.

[327] B. Liu, T. Luo, G. Mu, X. Wang, D. Chen, G. Shen, ACS Nano 2013, 7, 8051.

[328] H. D. Yoo, I. Shterenberg, Y. Gofer, G. Gershinsky, N. Pour, D. Aurbach, Energy Environ. Sci. 2013, 6, 2265.

[329] M.-C. Lin, M. Gong, B. Lu, Y. Wu, D.-Y. Wang, M. Guan, M. Angell, C. Chen, J. Yang, B.-J. Hwang, Nature 2015, 520, 324.

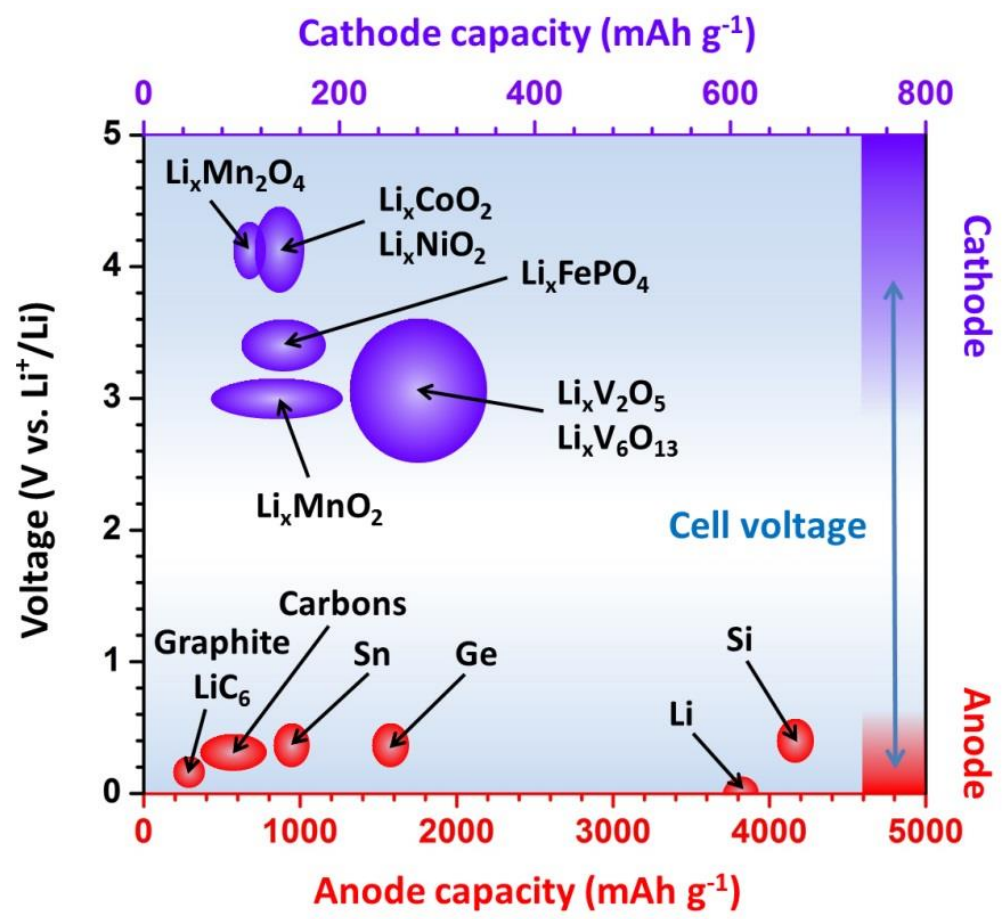

Figure 1. Diagram illustrating the capacities and electrochemical potentials of important cathode and anode materials with respect to Li metal and the cell voltage of LIBs. 


\section{WILEY-VCH}
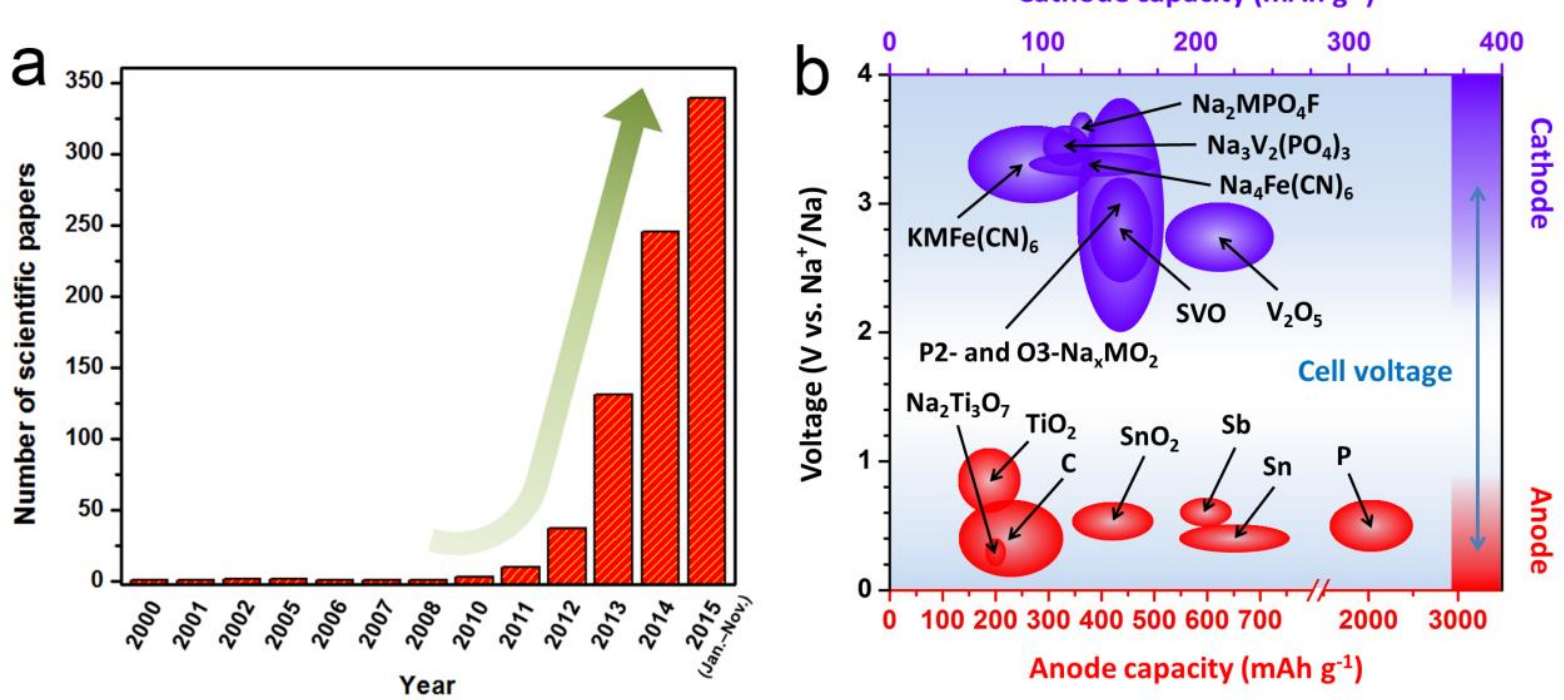

Figure 2. (a) The number of the scientific papers related to SIBs published since 2000. Data was collected using the ISI Web of Science. The number in 2015 is limited to the papers published from January to November. (b) Diagram illustrating the capacities and electrochemical potentials of important cathode and anode materials with respect to Na metal and the cell voltage of SIBs. (M: metal; SVO: sodium vanadates)
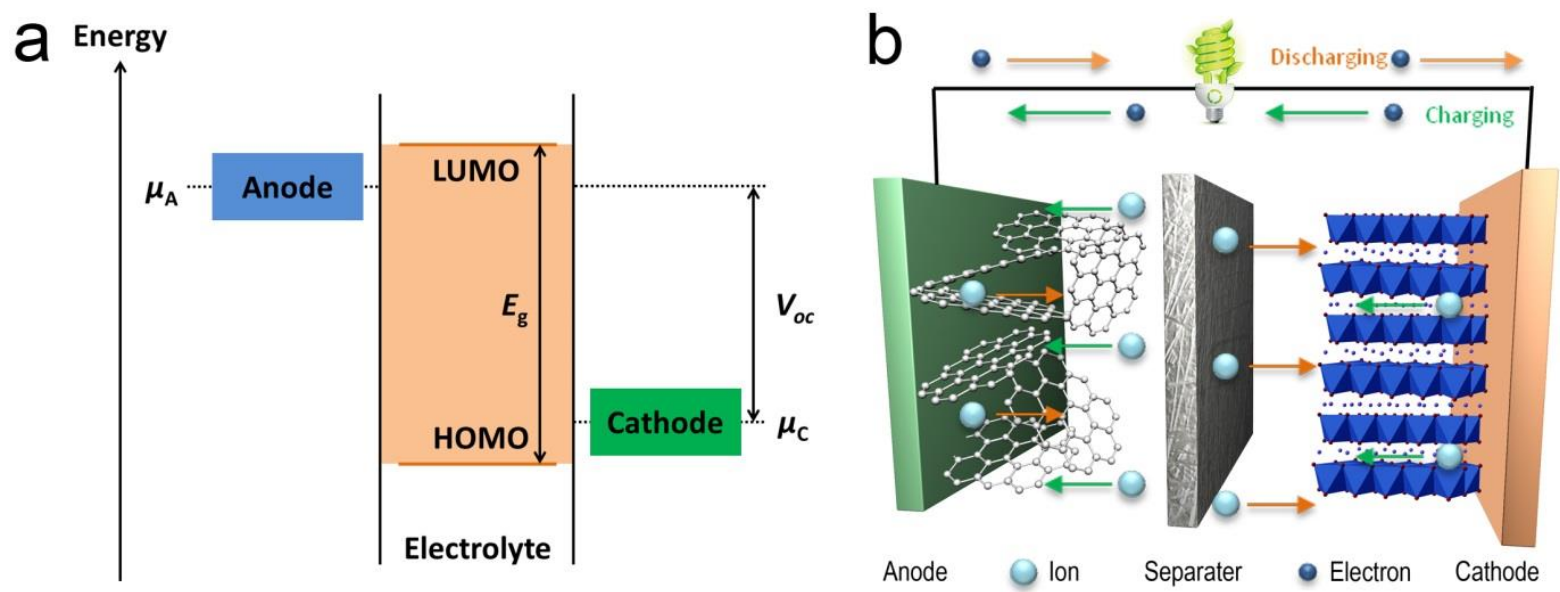

Figure 3. (a) Relative energy diagram of electrode potentials and electrolyte energy gap in rechargeable ion batteries. (b) Schematic illustration of rechargeable ion batteries. 


\section{WILEY-VCH}

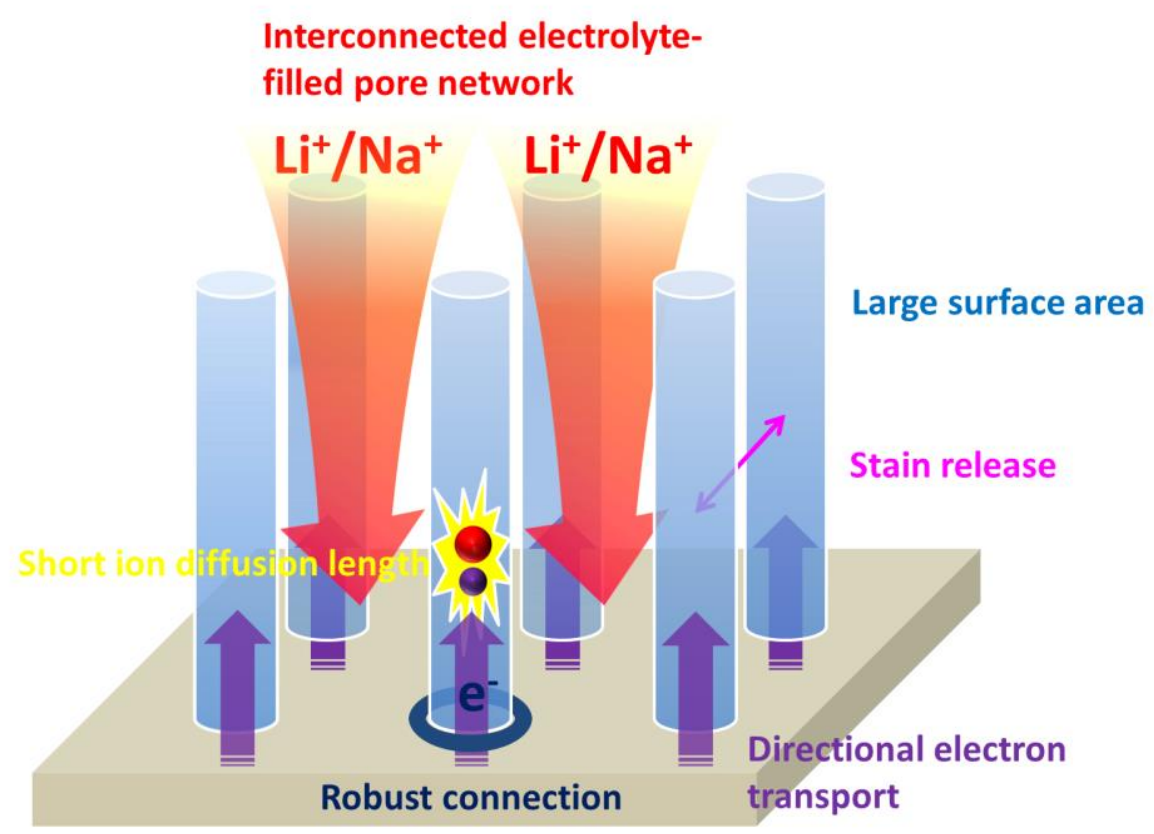

Figure 4. Schematic of the NAAs illustrating their prominent features.

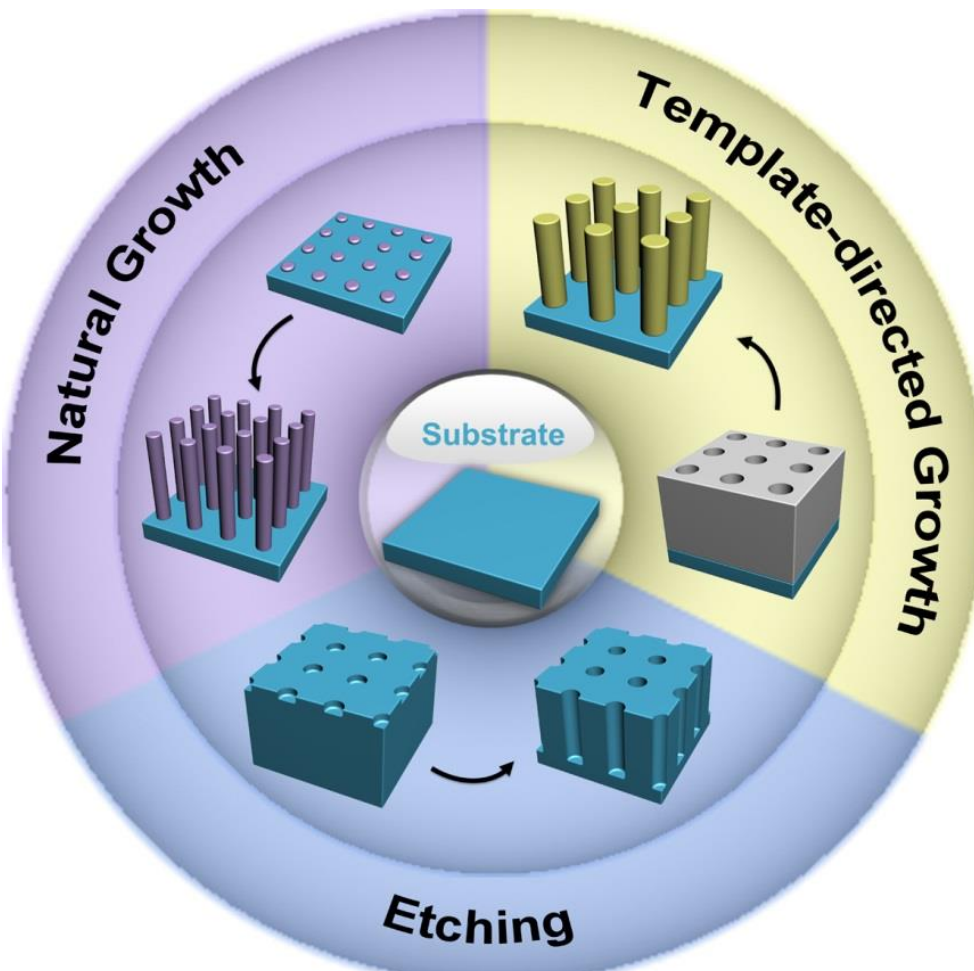

Figure 5. Schematic illustration of the fabrication of the NAA electrodes. 


\section{WILEY-VCH}
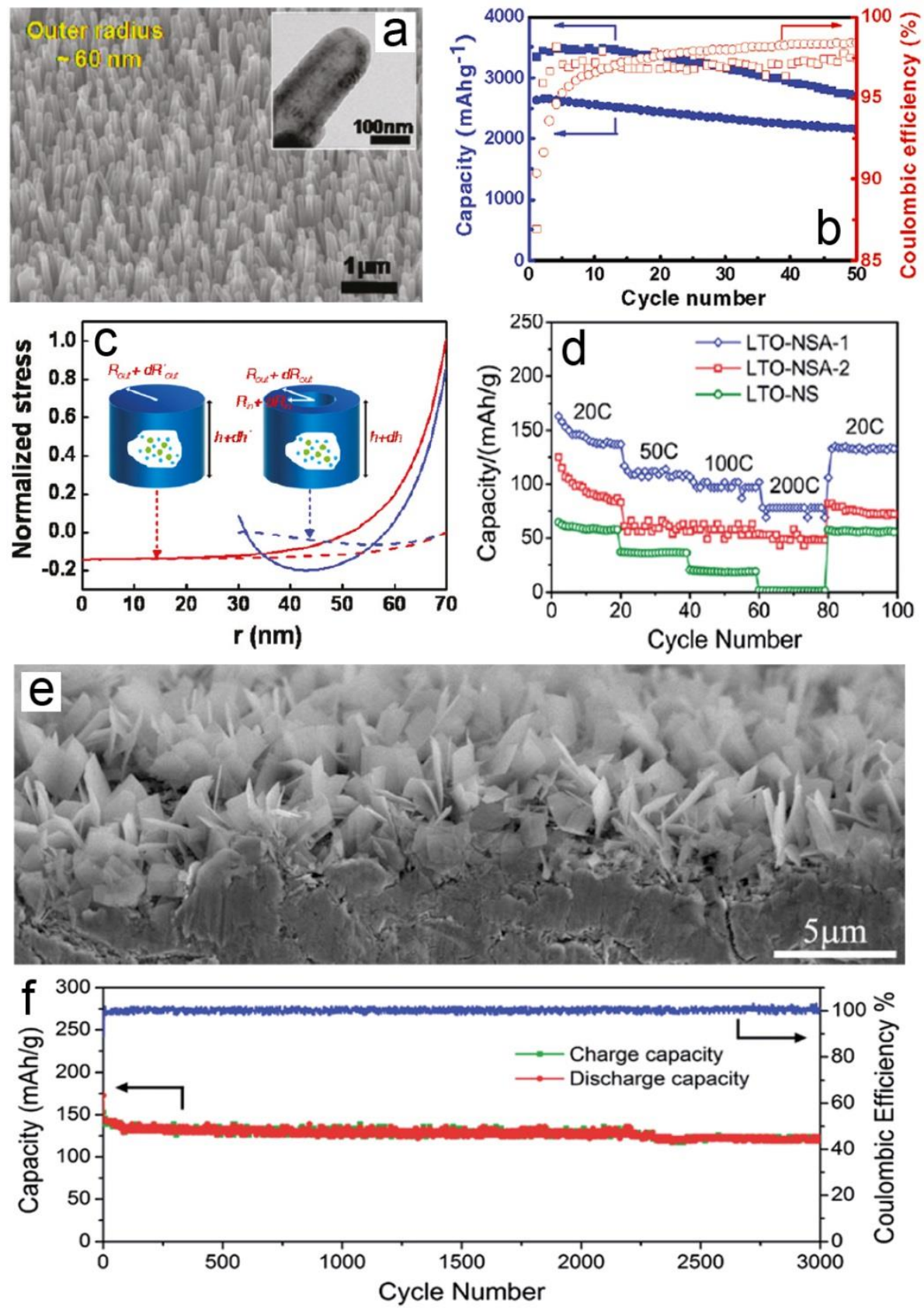

Figure 6. (a) SEM image of the vertically aligned Si nanotube arrays with an outside diameter of $60 \mathrm{~nm}$ on a SS substrate. Inset shows a TEM image of the sealed tip of a Si nanotube. (b) Cycling performance of the $\mathrm{Si}$ nanotube array electrode at 0.05 (square symbol) and $0.2 \mathrm{C}$ (circle symbol). (c) Computed distributions of stress in a fully lithiated nanowire (red) and nanotube (blue) with similar outer radii. Reproduced with permission. ${ }^{[266]}$ Copyright 2010, American Chemical Society. (d) Rate capability of different LTO nanosheet array electrodes. (e) Cross-sectional SEM image of the LTO nanosheet arrays standing on Ti foil. (f) Cycling performance of the LTO nanosheet array electrode for 3000 cycles at $50 \mathrm{C}$. Reproduced with permission. ${ }^{[16]}$ Copyright 2014, Royal Society of Chemistry. 


\section{WILEY-VCH}
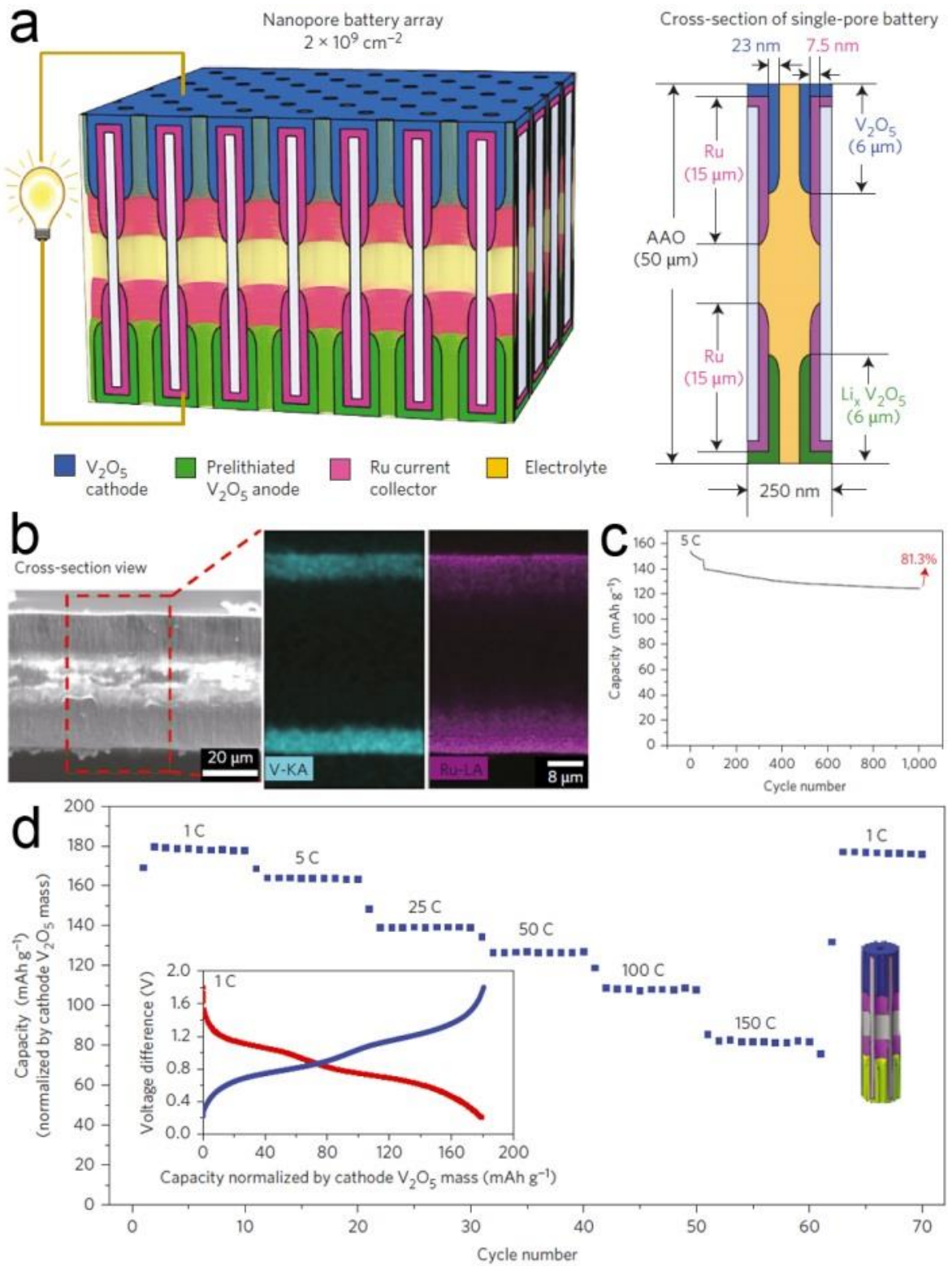

Figure 7. (a) Schematic illustration of the parallel nanopore battery array and cross-section of a single-pore battery. (b) EDS mapping of device cross-section, demonstrating that it in a symmetrical manner. (c) Cycling performance at $5 \mathrm{C}$ (capacity normalized by cathode $\mathrm{V}_{2} \mathrm{O}_{5}$ mass). (d) Rate capability. Inset: charge and discharge curves at $1 \mathrm{C}$. Reproduced with permission. ${ }^{[269]}$ Copyright 2014, Nature Publishing Group. 


\section{WILEY-VCH}
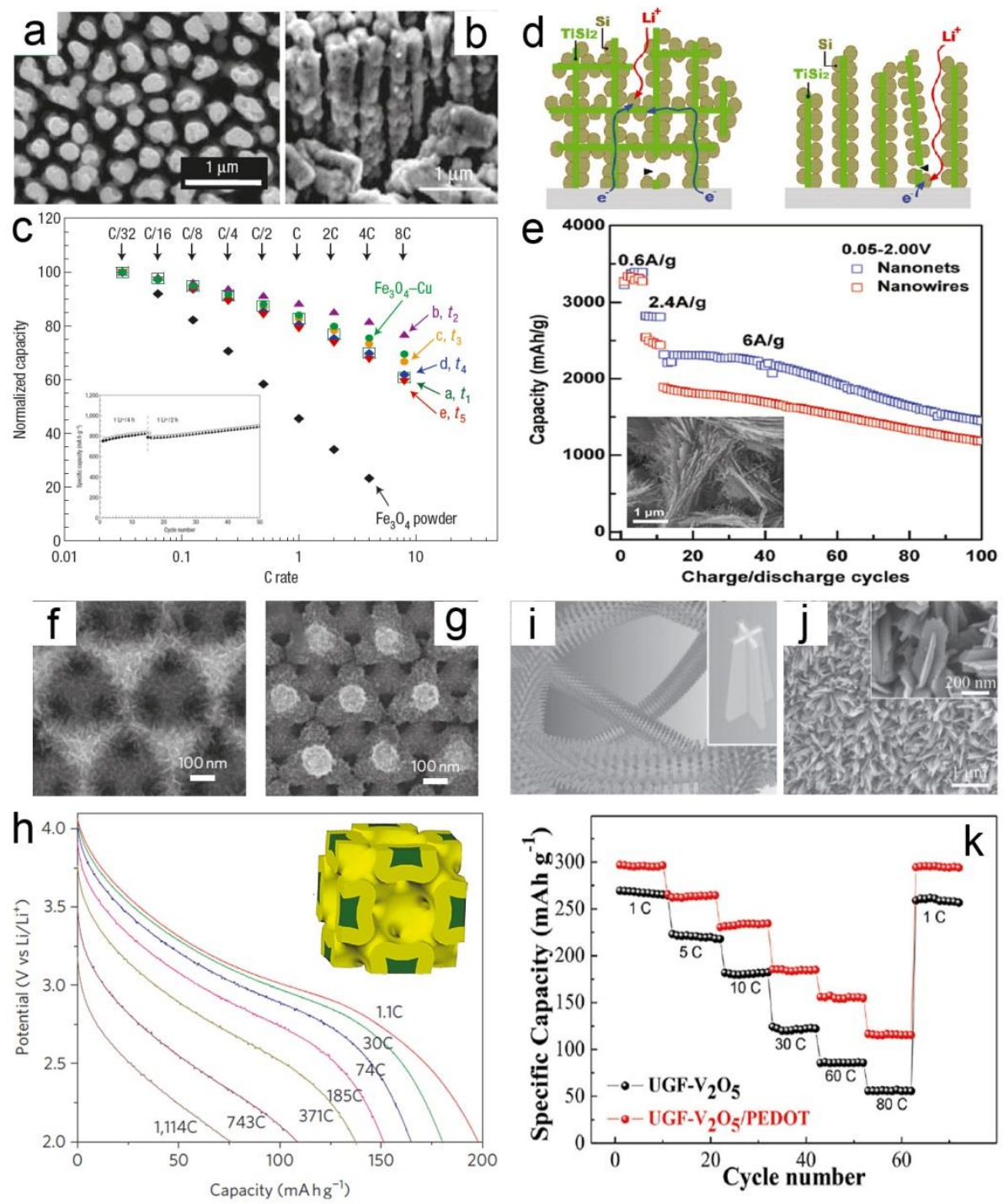

Figure 8. SEM image of $\mathrm{Cu}-\mathrm{Fe}_{3} \mathrm{O}_{4}$ core-shell nanoarray electrode before (a) and after (b) 100 cycles at a high rate $\left(1 \mathrm{Li}^{+} / 0.3 \mathrm{~h}\right)$, showing the good stability of the electrode. (c) Comparison of rate capability between the $\mathrm{Cu}-\mathrm{Fe}_{3} \mathrm{O}_{4}$ core-shell nanoarray electrodes with different deposition time and a $\mathrm{Fe}_{3} \mathrm{O}_{4}$ electrode on planar $\mathrm{Cu}$ foil. Reproduced with permission. ${ }^{[270]}$ Copyright 2006, Nature Publishing Group. (d) Schematic comparison of the nanonets- and nanowires-based systems, showing that the existence of other charge transport pathways within the nanonets can limit the impact on the overall capacity caused by the breakdown of single beam. (e) Comparison of cycling performance of the nanonets- and nanowires-based electrodes. Inset shows the SEM image of the $\mathrm{Si}_{-} \mathrm{TiSi}_{2}$ nanonets. Reproduced with permission. ${ }^{[271]}$ Copyright 2011, American Chemical Society. SEM images of the pristine (f) and lithiated (g) bicontinuous $3 \mathrm{D} \mathrm{MnO}_{2} / \mathrm{Ni}$ composite cathode. (h) Discharge curves of the lithiated $\mathrm{MnO}_{2} / \mathrm{Ni}$ cathode. Inset shows the schematic illustration of the bicontinuous electrode. The electrolytically active phase is yellow and the porous Ni current collector is green. Reproduced with permission. ${ }^{[240]}$ Copyright 2011, Nature Publishing Group. Schematic illustration (i), SEM image (j), and rate capability (k) of the UGF- $\mathrm{V}_{2} \mathrm{O}_{5} /$ PEDOT core/shell nanobelt arrays. Insets in (i) and (j) show the fine structures. Reproduced with permission. ${ }^{[295]}$ Copyright 2014, Wiley-VCH. 


\section{WILEY-VCH}
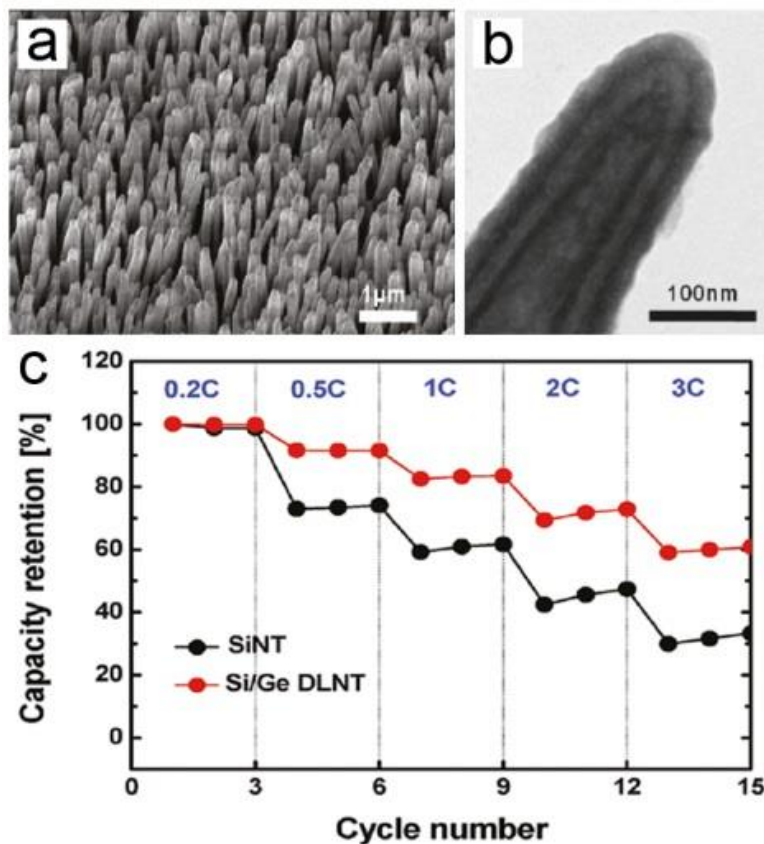
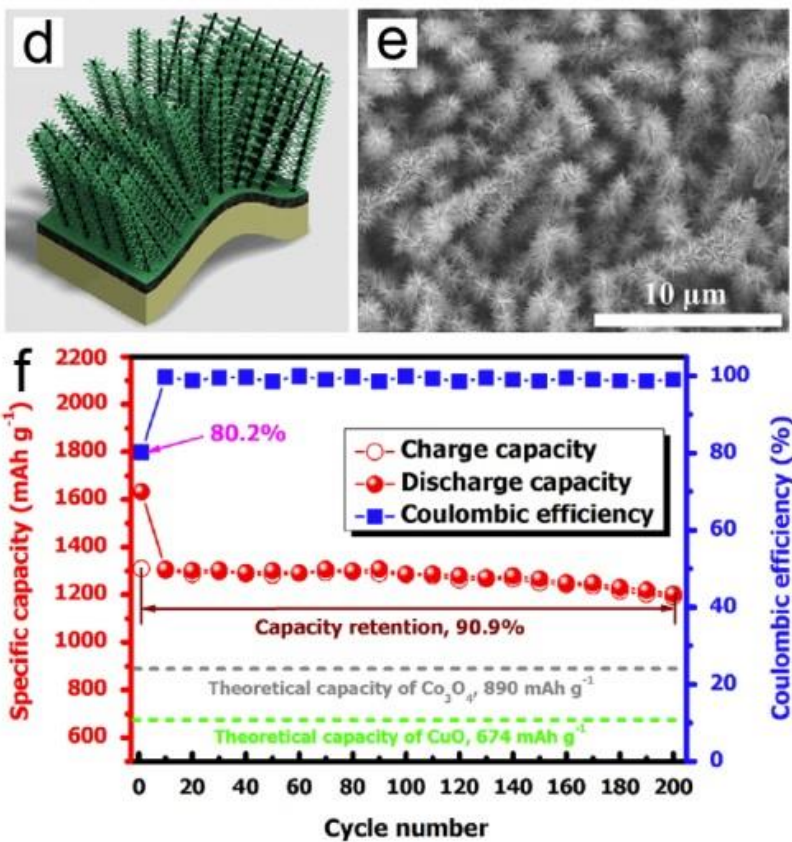

Figure 9. (a) SEM imge of the vertically aligned Si/Ge DLNT arrays on a SS substrate. (b) TEM image of a delithiated Si/Ge DLNT after cycles. (c) Rate capabilities of Si NT and Si/Ge DLNT array electrodes. Reproduced with permission. ${ }^{[208]}$ Copyright 2012, American Chemical Society. Schematic illustration (d) and SEM image (e) of $\mathrm{CuO} / \mathrm{Co}_{3} \mathrm{O}_{4}$ core/shell heterostructured nanowire arrays on $\mathrm{Ni}$ foam. (f) Cycling performance of the heterostructured array anode at $200 \mathrm{~mA} \mathrm{~g}^{-1}$. Reproduced with permission. ${ }^{[220]}$ Copyright 2014 , Elsevier.
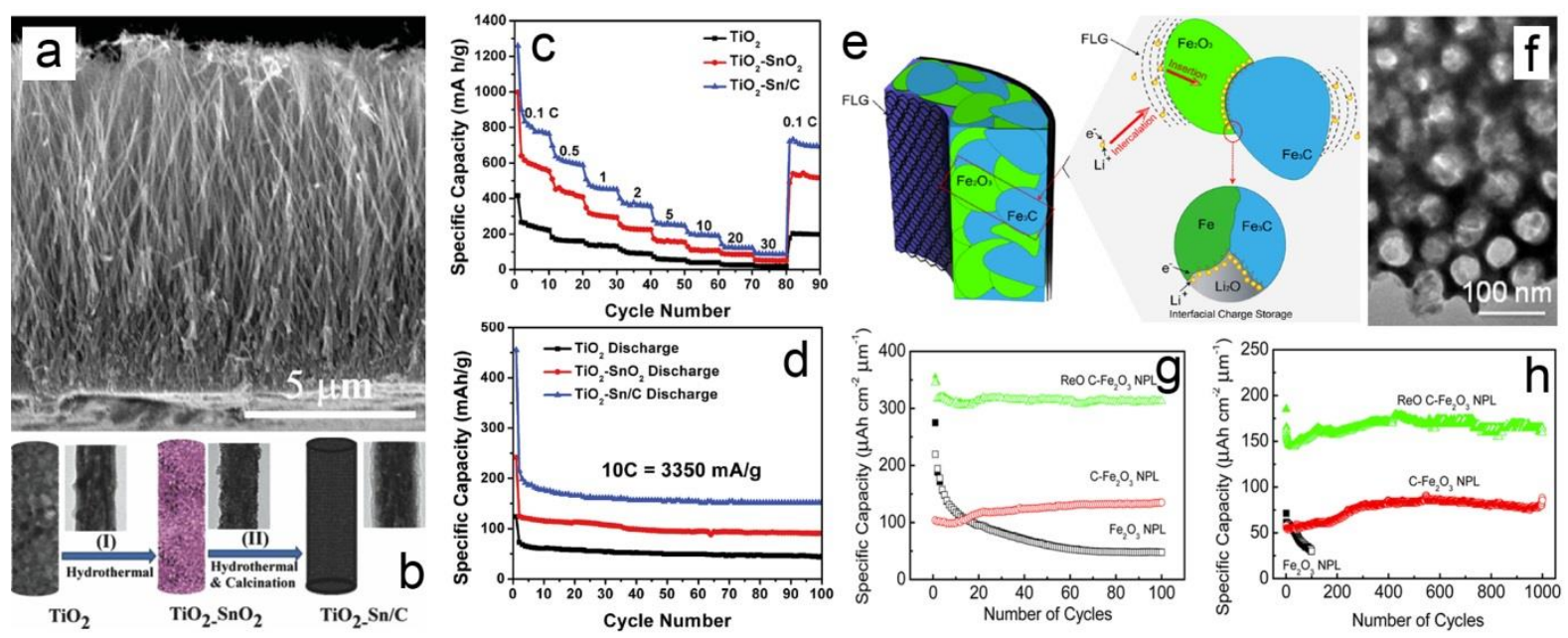

Figure 10. (a) SEM imge of the $\mathrm{TiO}_{2}-\mathrm{Sn} / \mathrm{C}$ core/shell nanowire arrays and the schematic of the fabrication process. Rate capability (c) and cycling performance (d) of different nanowire array anodes. Reproduced with permission. ${ }^{[99]}$ Copyright 2014, Wiley-VCH. Schematic illustration of the interfacial lithium storage mechanism (e) and SEM image (f) of the nanoporous $\mathrm{Fe}_{2} \mathrm{O}_{3} / \mathrm{Fe}_{3} \mathrm{C}$-graphene heterogeneous nanoarrays. Cycling performance at a rate of $50 \mu \mathrm{A} \mathrm{cm}{ }^{-2}(\mathrm{~g})$ and $1 \mathrm{~mA} \mathrm{~cm}{ }^{-2}(\mathrm{~h})$ of the array anodes. Reproduced with permission. ${ }^{[300]}$ Copyright 2014, American Chemical Society. 
WILEY-VCH
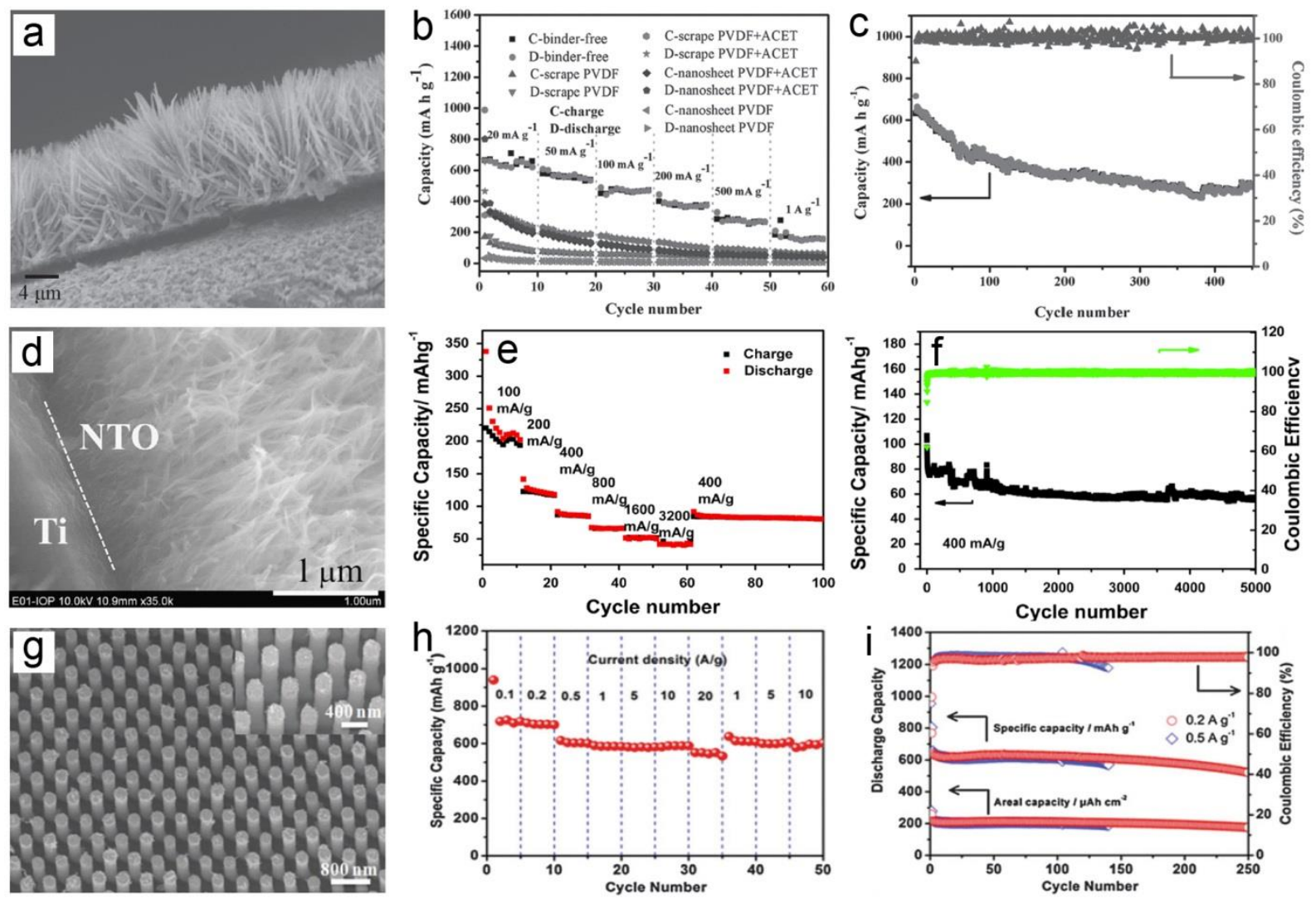

Figure 11. (a) Cross-sectional SEM image of the $\mathrm{CuO}$ nanorod arrays. (b) Rate capability of different $\mathrm{CuO}$ electrodes at various current densities. (c) Cycling performance of the CNA electrode at $200 \mathrm{~mA} \mathrm{~g}^{-1}$. Reproduced with permission. ${ }^{[305]}$ Copyright 2014, Wiley-VCH. Cross-sectional SEM image (d), rate capability (e), and cycling performance (f) of the NTO nanotube array anode. Reproduced with permission. ${ }^{[307]}$ Copyright 2014, Elsevier. SEM image (g), rate capability (h), and cycling performance (i) of the highly ordered Sb nanorod array anode. Reproduced with permission. ${ }^{[301]}$ Copyright 2015, Royal Society of Chemistry. 


\section{WILEY-VCH}

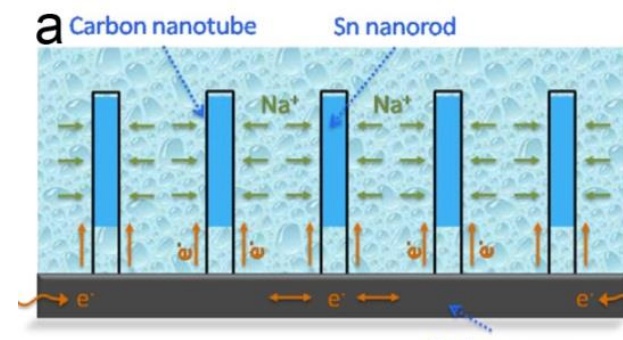

Carbon paper
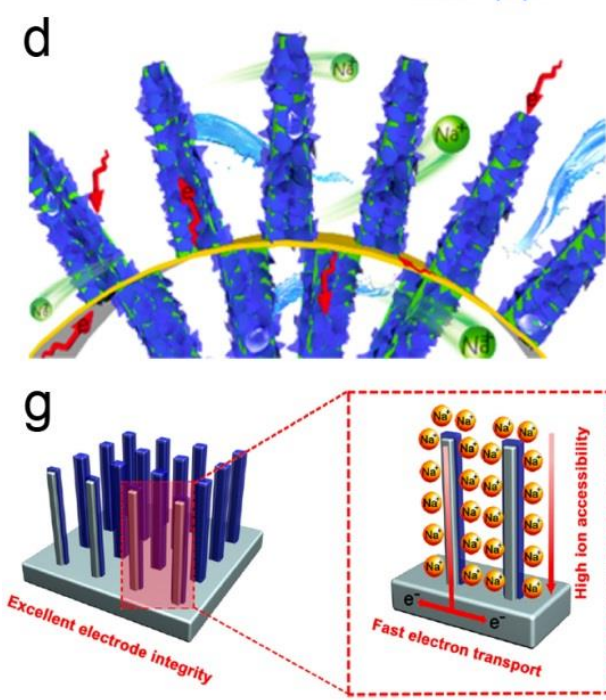
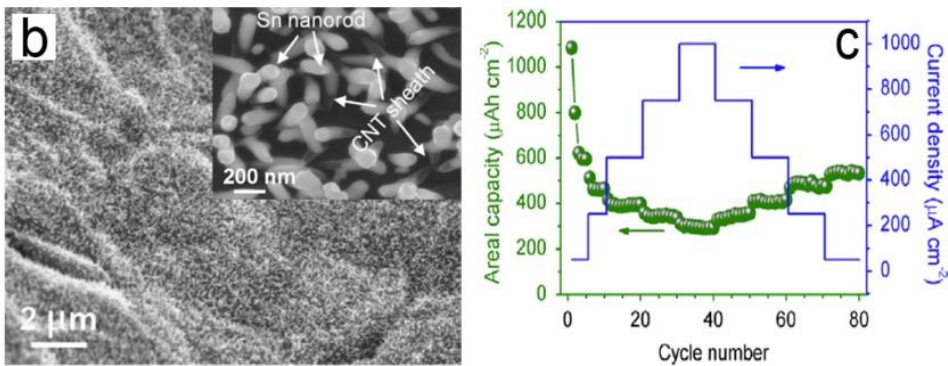

e
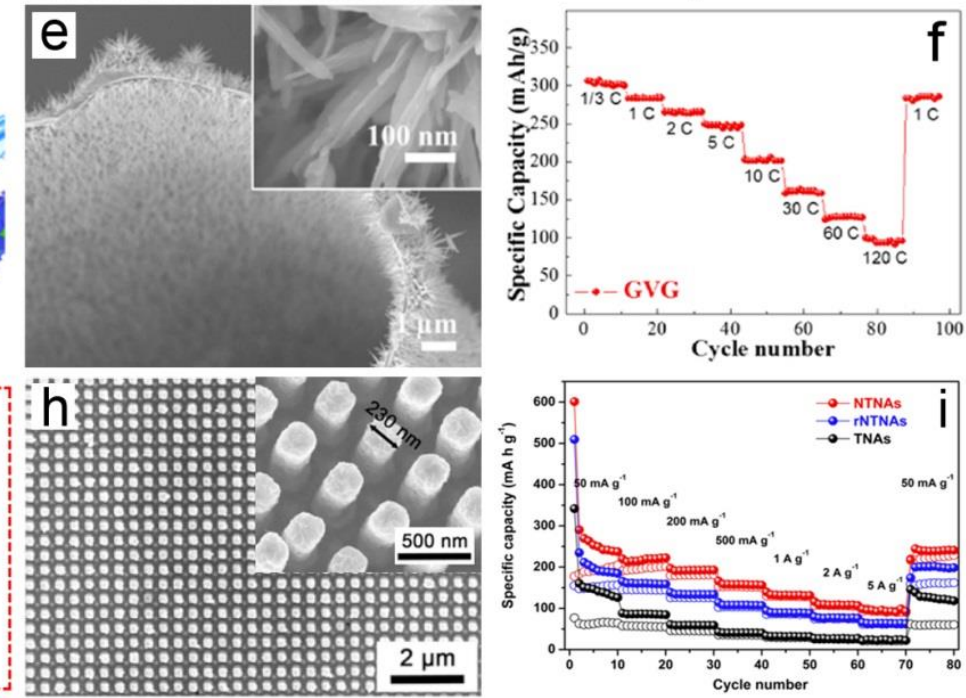

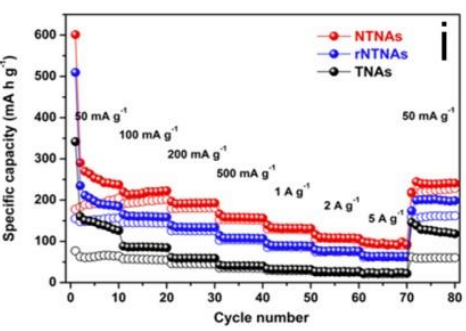

Figure 12. Schematic illustrations ( $a, d$ and g), SEM images (b, e and $h$, insets: fine structures), and rate capability (c, f and i) of the Sn@CNT-CP (a-c, reproduced with permission. ${ }^{[302]}$ Copyright 2015, Elsevier), GQDs-coated $\mathrm{VO}_{2}$ nanoarray (d-f, reproduced with permission. ${ }^{[308]}$ Copyright 2015, American Chemical Society), and $\mathrm{Ni}^{-\mathrm{TiO}_{2}}$ core-shell nanopillar array (g-i, reproduced with permission. ${ }^{[309]}$ Copyright 2015, American Chemical Society) electrodes. 


\section{WILEY-VCH}

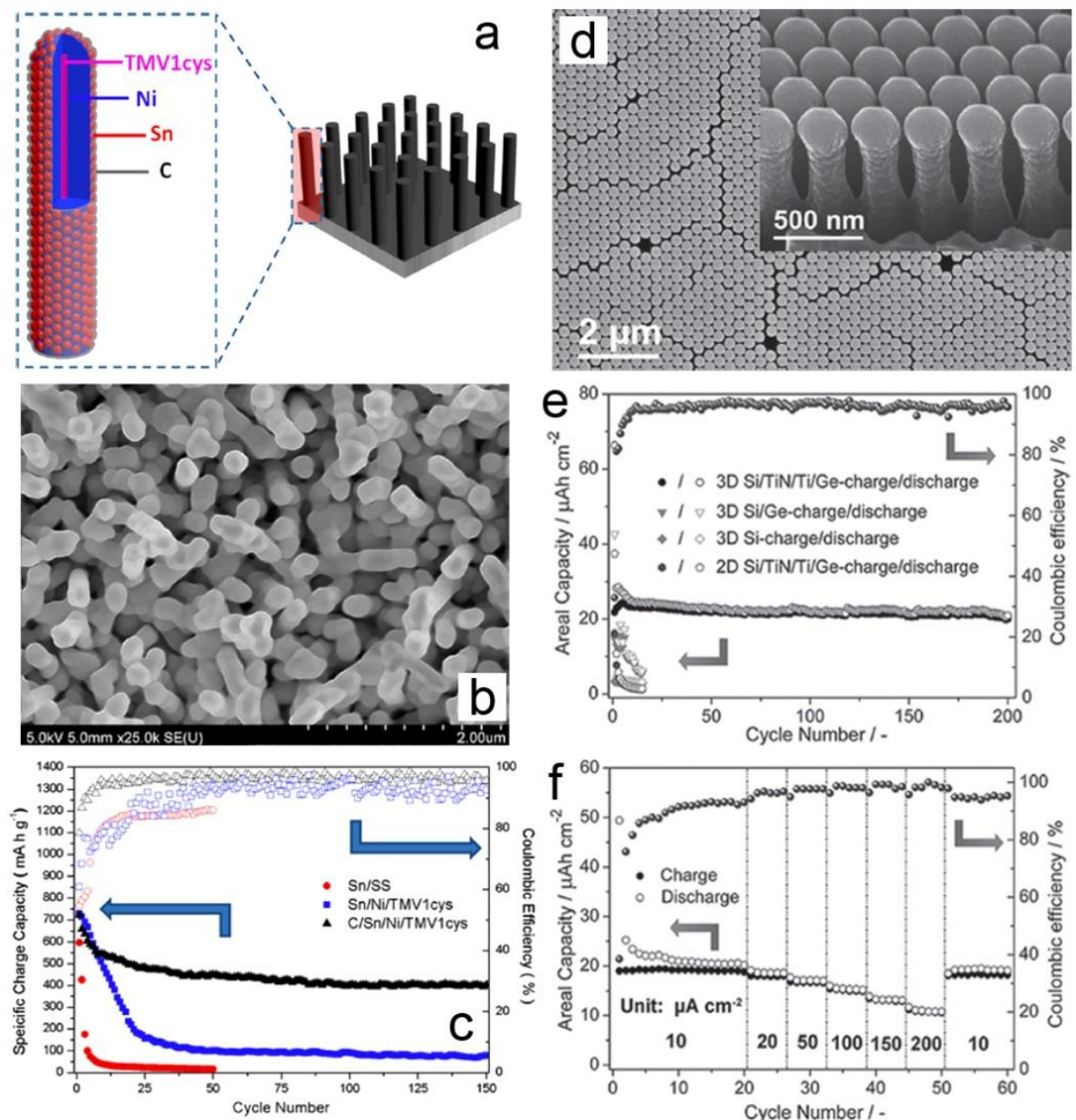

Figure 13. Schematic illustration (a), SEM image (b), and cycling performance (c) of the $\mathrm{C} / \mathrm{Sn} / \mathrm{Ni} / \mathrm{TMV} 1 \mathrm{cys}$ nanorod array electrode. Reproduced with permission. ${ }^{[304]}$ Copyright 2013 , American Chemical Society. (d) SEM image of the hexagonal match-like Si/TiN/Ti/Ge nanorod arrays on $\mathrm{Si}$ substrate. Inset shows the tilt view. (e) Comparison of the cycling performance of different Si-based 3D and 2D electrodes. (f) Rate capability of the $\mathrm{Si} / \mathrm{TiN} / \mathrm{Ti} / \mathrm{Ge}$ nanorod array electrode. Reproduced with permission. ${ }^{[303]}$ Copyright 2015, Wiley-VCH. 


\section{WILEY-VCH}

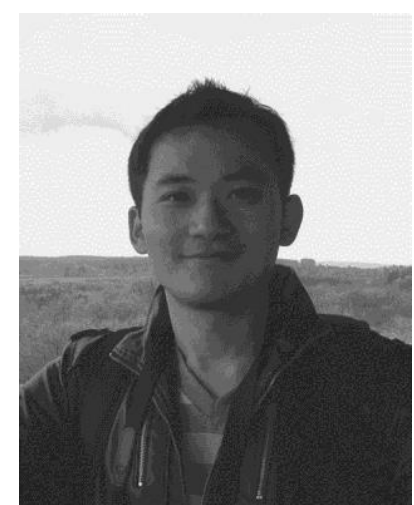

Yang Xu received his Ph.D. degree under the supervision of Prof. Yi Xie in the Hefei National Laboratory for Physical Sciences at the Microscale, University of Science and Technology of China in 2011. He joined Prof. Yong Lei's group in the Ilmenau University of Technology, Germany, as a senior scientist in 2013. His present research interest includes synthesis of functional nanomaterials and design of devices for electrochemical energy storage and conversion.

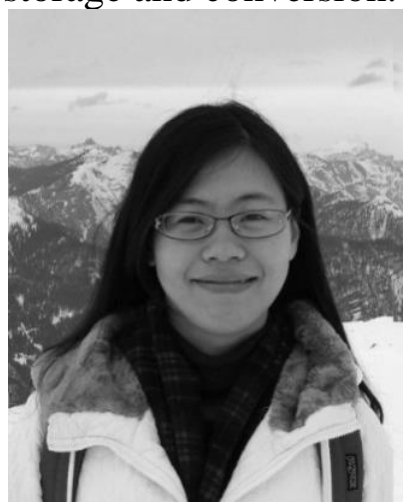

Min Zhou received her Ph.D. degree under the supervision of Prof. Yi Xie in the Department of Chemistry, University of Science and Technology of China in 2012. She is currently a postdoctoral fellow in Prof. Yong Lei's group in the Ilmenau University of Technology, Germany. Her research focuses on design of functional nanomaterials and devices for energy storage and conversion.

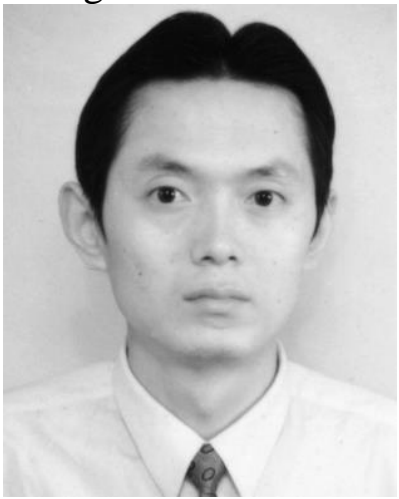

Yong Lei received his Ph.D. degree from the Chinese Academy of Sciences in 2001. After two years of postdoc research at Singapore-MIT Alliance, he worked as an Alexander von Humboldt Fellow at the Karlsruhe Institute of Technology in 2003-2006. Later he worked at the University of Muenster as a group leader (2006-2009) and a W1 professor (2009-2011). In 2011, he joined the Ilmenau University of Technology as a Chair Professor. His group currently focuses on template-based nanostructuring, energy-related and optoelectronic applications of functional nanostructures and surface nano-patterns. He received a few prestigious funding including European Research Council Grant and BMBF (Federal Ministry of Education and Research of Germany) ZIK project. 